\title{
Optical technologies for intraoperative neurosurgical guidance
}

\author{
Pablo A. Valdés, MD, PhD, ${ }^{1,2}$ David W. Roberts, MD, ${ }^{3}$ Fa-Ke Lu, PhD, ${ }^{1,4}$ and Alexandra Golby, MD1,5,6 \\ Departments of ${ }^{1}$ Neurosurgery and ${ }^{6}$ Radiology, and ${ }^{5}$ Dana Farber Cancer Institute, Harvard Medical School, Brigham and \\ Women's Hospital; ' 2 Department of Neurosurgery, Harvard Medical School, Boston Children's Hospital, Boston; ${ }^{4}$ Department of \\ Chemistry and Chemical Biology, Harvard University, Cambridge, Massachusetts; and ${ }^{3}$ Section of Neurosurgery, Geisel School \\ of Medicine at Dartmouth, Dartmouth-Hitchcock Medical Center, Lebanon, New Hampshire
}

\begin{abstract}
Biomedical optics is a broadly interdisciplinary field at the interface of optical engineering, biophysics, computer science, medicine, biology, and chemistry, helping us understand light-tissue interactions to create applications with diagnostic and therapeutic value in medicine. Implementation of biomedical optics tools and principles has had a notable scientific and clinical resurgence in recent years in the neurosurgical community. This is in great part due to work in fluorescenceguided surgery of brain tumors leading to reports of significant improvement in maximizing the rates of gross-total resection. Multiple additional optical technologies have been implemented clinically, including diffuse reflectance spectroscopy and imaging, optical coherence tomography, Raman spectroscopy and imaging, and advanced quantitative methods, including quantitative fluorescence and lifetime imaging. Here we present a clinically relevant and technologically informed overview and discussion of some of the major clinical implementations of optical technologies as intraoperative guidance tools in neurosurgery.

http://thejns.org/doi/abs/10.3171/2015.12.FOCUS15550
\end{abstract}

KEY WORDS fluorescence-guided surgery; fluorescence lifetime; Raman spectroscopy and imaging; diffuse reflectance spectroscopy and imaging; laser speckle contrast imaging; optical coherence tomography; biomedical optics; image-guided surgery

$\mathrm{B}$ IOMEDICAL optics is a broadly interdisciplinary field at the interface between optical engineering, biophysics, computer science, medicine, biology, and chemistry, helping us understand light-tissue interactions to create applications with diagnostic and therapeutic value in medicine. Implementation of optical tools and principles in the neurosurgical operating theater dates back to the early part of the 20th century, when Moore used fluorescein sodium as a fluorescent biomarker for intraoperative identification of gliomas. ${ }^{92}$ Applications of biomedical optics have had a notable scientific and clinical resurgence in recent years in the neurosurgical community. The most well-known example is the use of fluorescence imaging for surgical guidance in brain tumor resection, culminating in a Phase III clinical trial by Stummer and colleagues using 5-aminolevulinic acid-induced protoporphyrin IX (ALA-PpIX) fluorescence for glioblastoma multiforme (GBM) resection. This major study subsequently prompted a collection of work worldwide utilizing this technology clinically to help improve the extent of resection.
In addition to this initial implementation of fluorescence technology and biomarker use in major trials to date, multiple additional optical tools or technologies are beginning to enter the clinical arena, including diffuse reflectance spectroscopy and imaging, optical coherence tomography (OCT), Raman spectroscopy, and quantitative methods, including quantitative fluorescence, lifetime imaging, and beyond (Tables 1 and 2). Here we present a clinically relevant and technologically informed overview of some of the major clinical implementations of optical technologies as intraoperative guidance tools in neurosurgery.

\section{Fluorescence}

\section{Wide-Field Imaging}

Exogenous Fluorescent Markers: ALA-PpIX, Fluorescein, and Beyond

Fluorescence-guided surgery dates back to 1948 when Moore et al..$^{92}$ used fluorescein sodium in 46 patients with

ABBREVIATIONS ALA-PpIX = 5-aminolevulinic acid-induced protoporphyrin IX; BBB = blood-brain barrier; CARS = coherent anti-Stokes Raman scattering; CBF = cerebral blood flow; CCD = charge-coupled device; GBM = glioblastoma multiforme; GTR = gross-total resection; ICG = indocyanine green; LSCI = laser speckle contrast imaging; NIR = near-infrared; OCT = optical coherence tomography; SRS = stimulated Raman scattering; $\lambda$ em = emission wavelength; $\lambda$ ex = excitation wavelength.

SUBMITTED October 30, 2015. ACCEPTED December 10, 2015.

INCLUDE WHEN CITING DOI: 10.3171/2015.12.FOCUS15550. 
TABLE 1. Optical technologies in neurosurgery

\begin{tabular}{|c|c|c|c|c|}
\hline Technology \& Contrast & Mechanism & Contrast Agent & Tools & Biomolecules \\
\hline \multicolumn{5}{|l|}{ Fluorescence } \\
\hline Steady state & $\begin{array}{l}\text { Tissue is interrogated with light at a } \lambda \text { ex leading to absorption with } \\
\text { subsequent emission at a longer } \lambda \text { em based on the intrinsic } \\
\text { excitation-emission properties of a fluorescent molecule }\end{array}$ & $\begin{array}{l}\text { Fluorophore, endo or exo, } \\
\text { e.g., PpIX, fluorescein, } \\
\text { NAD(P)H }\end{array}$ & $\begin{array}{l}\text { Spect, micro, } \\
\text { WF }\end{array}$ & Endo, exo \\
\hline Time resolved & $\begin{array}{l}\text { Tissue is interrogated with light at a } \lambda \text { ex leading to absorption with } \\
\text { subsequent emission at a longer } \lambda \text { em based on the intrinsic } \\
\text { excitation-emission properties of a fluorescent molecule, } \\
\text { with measurement of the average time electrons spend in an } \\
\text { excited state prior to fluorescence emission }\end{array}$ & $\begin{array}{l}\text { Fluorophore, endo or exo, } \\
\text { e.g., PplX, fluorescein, } \\
\text { NAD(P)H }\end{array}$ & Spect, micro & Endo \\
\hline \multicolumn{5}{|l|}{ Reflectance } \\
\hline Reflectance & $\begin{array}{l}\text { Tissue is interrogated with light at a predefined } \lambda \text { with reflected } \\
\text { light at corresponding } \lambda \text {, undergoing differential levels of } \\
\text { absorption and scattering based on tissue physiology to create } \\
\text { maps such as blood volume, blood oxygenation, tissue attenu- } \\
\text { ation, and tissue scattering }\end{array}$ & $\begin{array}{l}\text { Endo chromophores, e.g., } \\
\text { oxyhemoglobin, deoxy- } \\
\text { hemoglobin, scattering }\end{array}$ & $\begin{array}{l}\text { Spect, micro, } \\
\text { WF }\end{array}$ & Endo \\
\hline \multicolumn{5}{|l|}{ Raman } \\
\hline $\begin{array}{l}\text { Classical } \\
\text { CARS } \\
\text { SRS } \\
\text { SERS }\end{array}$ & $\begin{array}{l}\text { Tissue is interrogated with light where a small amount of this inci- } \\
\text { dent light at a specific } \lambda \text { is scattered at a different } \lambda \text { as a func- } \\
\text { tion of the vibrational energies of molecular bonds in tissues }\end{array}$ & $\begin{array}{l}\text { Molecular bonds, e.g., } \\
\text { DNA, lipids, proteins }\end{array}$ & Spect, micro & Endo \\
\hline
\end{tabular}

Endo = endogenous; exo = exogenous; micro = microscopy; SERS = surface-enhanced Raman scattering; spect = spectroscopy; WF = wide-field imaging; $\lambda=$ wavelength; $\lambda \mathrm{em}=$ emission wavelength; $\lambda \mathrm{ex}=$ excitation wavelength .

brain tumors as a means for tumor tissue visualization. In 1982 Murray reported the use of fluorescein sodium as a surgical adjunct in 23 patients to distinguish between neoplastic versus necrotic tissue. ${ }^{95}$ Murray concluded that his results were in agreement with the work by Moore et al., and that use of fluorescein might prove beneficial in surgical guidance for tumor resection. It was not until the end of the 20th century, when Walter Stummer presented a preliminary, groundbreaking study using ALA-PpIX fluorescence in patients with GBM, that fluorescence reemerged as a tentatively powerful intraoperative surgical adjunct in neurosurgery. Stummer was familiar with the work in the field of photodynamic therapy, where exogenous administration of ALA was noted to preferentially accumulate PpIX in malignant tissues. ${ }^{48,134}$ Stummer and colleagues performed an initial preliminary study involving 9 patients with gliomas. The authors reported on the utility of ALA-PpIX fluorescence for the detection and removal of residual tumor tissue in 7 of 9 patients, noting no residual in situ fluorescence, no postoperative MRI contrast enhancement, and $85 \%$ sensitivity, $100 \%$ specificity, and $90 \%$ accuracy. ${ }^{134}$

Briefly, patients are administered an oral dose of ALA
2-3 hours prior to the induction of anesthesia, leading to overproduction and accumulation of PpIX in tumor tissue, specifically in high-grade gliomas. ALA is a precursor in the heme biosynthetic pathway, and its exogenous administration bypasses a rate-limiting step (i.e., synthesis of ALA by ALA synthase) and leads to the overproduction of PpIX..$^{20}$ Violet light (excitation wavelength $[\lambda$ ex $]=405$ $\mathrm{nm}$ ) illuminates tissue to excite PpIX at its main excitation absorption peak, and PpIX emits a red-pink fluorescence (emission wavelength $[\lambda \mathrm{em}]=620-710 \mathrm{~nm}$ ). ${ }^{151}$ Multiple mechanisms and actuators have been posited as contributors to the selective accumulation of PpIX in tumors, including enzymatic modifications (e.g., ferrochelatase, porphobilinogen deaminase), transporter regulation, varying cellular states like hypoxia and acidic environments, increased cellular growth, glucose levels, metabolic and structural changes. ${ }^{6}, 20,39,50,94,101,103,138,151,153,159,160$

Subsequently, Stummer et al. performed a larger study involving 52 patients with high-grade gliomas, ${ }^{131}$ which garnered clinical excitement by demonstrating $63 \%$ grosstotal resection (GTR) on postoperative contrast-enhanced imaging ${ }^{131}$ (Fig. 1). The authors then carried out a landmark Phase III randomized control trial involving 270 patients

TABLE 2. Optical instrumentation in neurosurgery

\begin{tabular}{ccclc}
\hline Instrumentation & FOV & Resolution & Intraop Implementation & Technology \\
\hline Spect & $\sim \mathrm{mm}$ & $\sim \mathrm{mm}$ to sub-mm & Contact handheld probes & $\begin{array}{c}\text { Fluor intensity, fluor lifetime, diffuse reflec- } \\
\text { tance, Raman }\end{array}$ \\
\hline Micro & $\sim \mu \mathrm{m}$ & $\sim \mu \mathrm{m}$ & Contact handheld probes, noncontact imaging systems & Fluor intensity, fluor lifetime, OCT, Raman \\
\hline WF & $\sim \mathrm{cm}$ & $\sim \mathrm{mm}$ & Microscopes, noncontact imaging systems & Fluor, diffuse reflectance, LSCl, OCT \\
\hline
\end{tabular}

Fluor = fluorescence; FOV = field of view; intraop = intraoperative. 

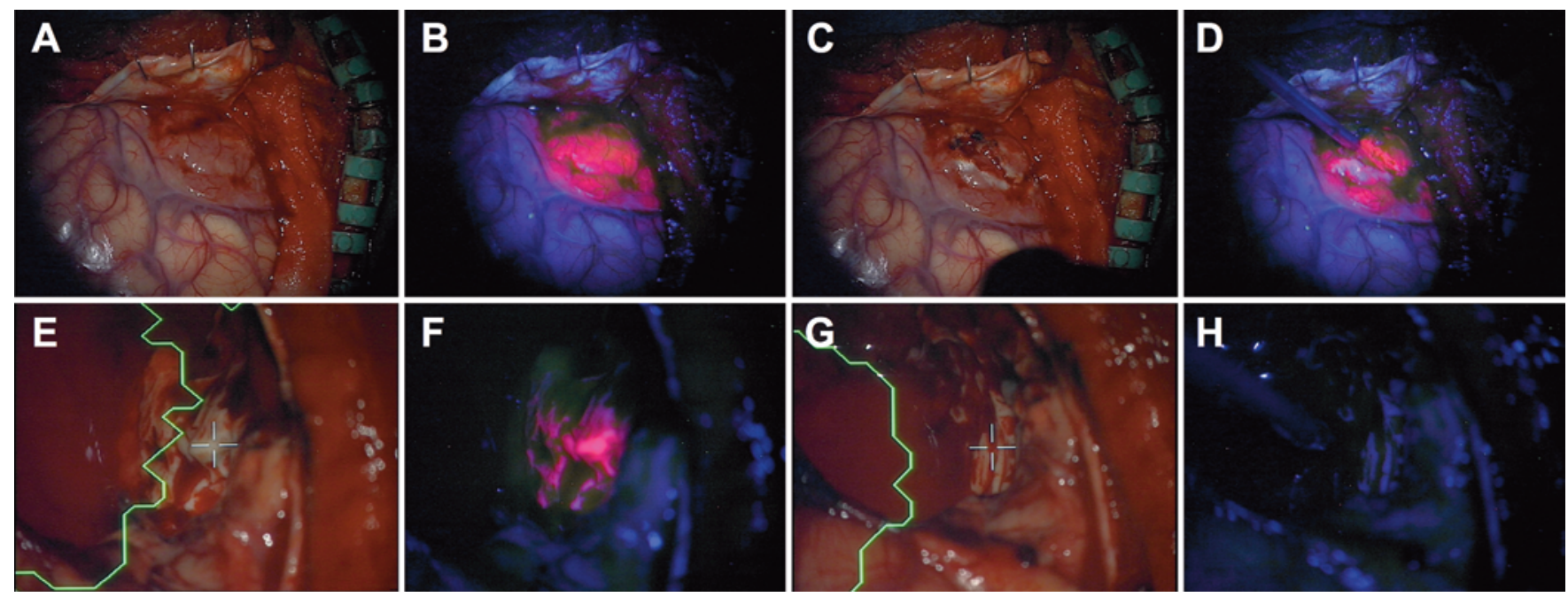

FIG. 1. Intraoperative paired white light and fluorescence mode images during multiple stages of PpIX fluorescence-guided resection of a GBM, showing strong visible PpIX fluorescence at the beginning ( $\mathbf{A}$ and $\mathbf{B})$, middle (C and $\mathbf{D})$, and near end $(\mathbf{E}$ and $\mathbf{F})$ of surgery, and no visible fluorescence at the end ( $\mathbf{G}$ and $\mathbf{H}$ ) (heads up display contour lines in green). Heads up display corresponding to segmented contrast-enhancing tumor demonstrates strong PpIX fluorescent tissue outside $(F)$ the segmented region near the end of the resection and no visible PpIX fluorescent tissue at the end $(\mathrm{H})$. The patient underwent fluorescence-guided resection under a protocol approved by the institutional review board at Dartmouth-Hitchcock Medical Center.

in 17 centers, who were randomized to a group undergoing ALA-PpIX fluorescence-guided surgery and a group undergoing conventional white light-guided surgery. The trial results were notable for GTR of contrast-enhancing tumor on postoperative imaging in $65 \%$ of patients undergoing ALA-PpIX fluorescence guidance compared with $36 \%$ of patients in the white light group $(\mathrm{p}<0.001)$, and progression-free survival of $41 \%$ versus $21.1 \%(p<0.003)$ for fluorescence versus white light groups, respectively. ${ }^{132}$ In a subsequent reanalysis of the data to look at morbidity, no statistically significant difference in long-term morbidity was found between the fluorescence and white light groups. ${ }^{102,133,136,138}$

ALA-PpIX use for GBM has become widespread in locations where it has met clinical approval, such as in countries in the European Union. Numerous studies have investigated the relationship of ALA-PpIX fluorescence and tumor location, histopathological correlates, and relationship with other intraoperative aids (e.g., intraoperative MRI, brain deformation modeling, functional mapping). $26,46,49,51,115,116,122,127,144-146,148,149,152-154,156,164$ Studies have mostly noted the utility of ALA-PpIX in high-grade gliomas, specifically in GBM..$^{134,150}$ Additional work not powered for survival analysis noted beneficial diagnostic value in other tumor subtypes including meningiomas and metastases. Recent technological advances have provided exciting preliminary evidence regarding the utility of ALA-PpIX in additional tumor histologies previously thought to not be amenable to ALA-PpIX fluorescenceguided surgery, i.e., low-grade gliomas. The clinical value of ALA-PpIX fluorescence imaging with state of the art tools rests on the premise that it provides the surgeon with a tool for 1) immediate intraoperative feedback regarding the presence or absence of tumor in real-time mode; 2 ) reliable correlation between imaging features (i.e., positive fluorescence with high positive predictive value for tumor) and histopathology; and 3) ease of integration into the neurosurgical workflow.

Numerous exogenous agents have been used clinically in neurosurgery, including fluorescein sodium, indocyanine green (ICG), mTHPC, Photofrin, and PpIX.2225,48,58,68,93,111,112,132,169,174 Recent work notes renewed interest in fluorescein sodium for surgical guidance in resection of brain tumors, ${ }^{23,75,79,112,124}$ including gliomas, ${ }^{8,70}$ metastasis, ${ }^{98}$ and meningiomas, ${ }^{27}$ with reports noting varying specificities and sensitivities. Fluorescein sodium is administered intravenously, and accumulation follows the principles of the enhanced retention and permeability effect and is dependent on a compromised blood-brain barrier (BBB) ${ }^{79}$ such that wherever there is blood or a disrupted barrier, fluorescein will accumulate in tissue, making it a potentially highly nonspecific biomarker. Once it accumulates, fluorescein sodium displays a green fluorescence that can be visualized either by the naked eye or via multiple different technological adaptations to current systems (Fig. 2). In a recent commentary, Stummer ${ }^{129}$ discusses the limitations and care required in interpreting results using fluorescein sodium as a surgical adjunct in neurosurgery. Fluorescein has the potential to be a highly nonspecific biomarker that will accumulate in any areas with BBB disruption or blood leakage, and as such it will accumulate irrespective of tumor cell presence, e.g., in normal neuraxis regions without a BBB, such as choroid plexus, or in abnormal tissues such as edema, necrosis, leaking vessels, and bleeding vessels without hemostasis intraoperatively. A main concern in using this compound is that, given its limited specificity, surgeons would risk removal of viable, normal tissue and, given sensitivity concerns, would risk leaving behind tumor tissue.

A wealth of information is accumulating in the literature on the diagnostic capabilities of the 2 most commonly used intraoperative fluorescence imaging agents, ALA- 

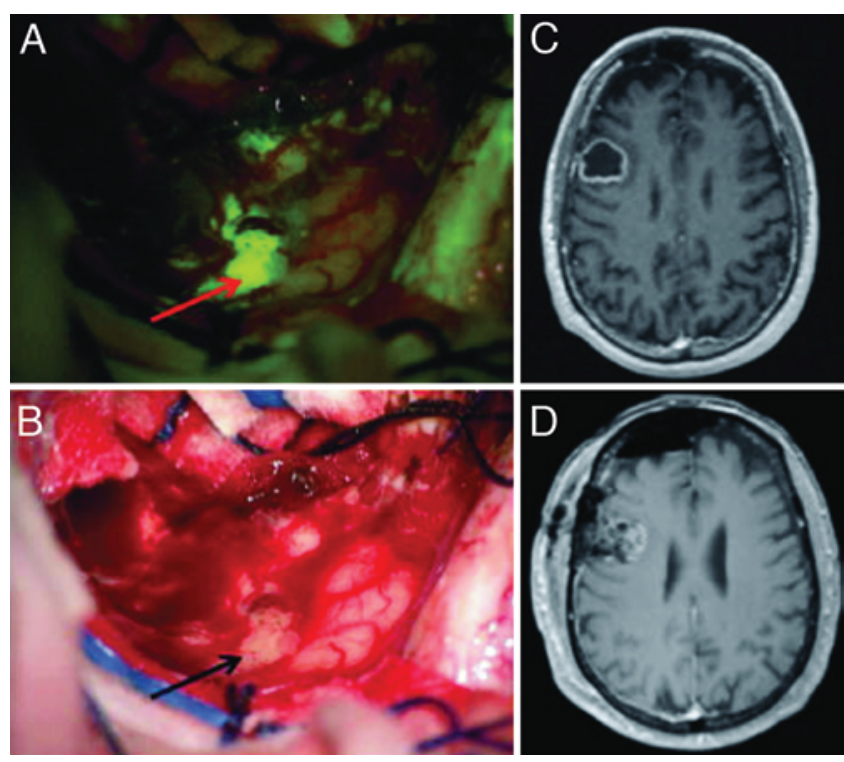

FIG. 2. A and B: Intraoperative images of fluorescein sodium in human gliomas showing intraoperative green fluorescence in the tumor bed with their corresponding T1-weighted contrast-enhanced MR images ( $\mathbf{C}$ and D). Green fluorescence in the tumor bed (arrows) corresponds to tumor tissue but nonspecific diffuse fluorescence is also visible at the dural flap. Reproduced with permission from Acerbi et al: Neurosurg Focus 36(2):E5, 2014

PpIX and fluorescein. Currently, the most numerous and thorough studies have been on the diagnostic capabilities of ALA-PpIX (e.g., accuracy, sensitivity, specificity, negative predictive value, and positive predictive value) using both visible and quantitative tools (see Quantitative Versus Qualitative Fluorescence); meanwhile, in comparison, the data on fluorescein are more limited and the results and conclusion pertaining to this imaging agent should be interpreted as such. 2,22,42,92,95,99,112,116,131,135,148,150,156,167 Tables 3 and 4 provide a general overview of key studies using PpIX and fluorescein, respectively, and the associated derived diagnostic capabilities of these agents.

ICG has seen limited use in the resection of tumors, enabling evaluation of tumoral and peritumoral blood flow and vasculature, yet detailed diagnostic studies have not accrued in similar volume to that of ALA-PpIX and fluorescein. ${ }^{29,61,63,78,107-109,165,166}$ Unlike PpIX and fluorescein, which both emit fluorescence in the visible spectrum (i.e., visible spectrum 400-720 nm), ICG has the advantage of excitation and emission in the near-infrared (NIR) region of the spectrum. ICG has a major excitation peak at approximately $\lambda \mathrm{ex}=800 \mathrm{~nm}$ and a main emission peak at approximately $\lambda \mathrm{em}=830-840 \mathrm{~nm}$. ${ }^{114,151,171}$ The NIR properties of ICG enables visualization of fluorophore situated deeper in the tissue given that longer wavelength excitation and emission light undergoes less absorption than shorter wavelength, visible light, but requires special cameras and instrumentation to visualize the emitted fluorescence (i.e., cannot be visualized with the naked eye).

These initial studies as well as the majority of subsequent clinical work using fluorescence guidance have employed wide-field imaging approaches (i.e., imaging via a surgical microscope of macroscopic structures and field of views in the order of centimeters) (Tables 1 and 2). Wide-field fluorescence imaging has the advantage of improved field of view with immediate visual feedback to the surgeon, which has exploited such fluorophores as PpIX,,$^{32,33,96,102,116,127,130-133,136,148,153-156}$ ICG, ${ }^{29,44,63,85}$ and fluorescein. $1,22,23,65,71,74-76,92,98,111,112,124,125,128$ For example, ALAPpIX fluorescence provides the surgeon with immediate visualization of a tumor, noting areas with significant PpIX accumulation as a red-pink fluorescence and areas without significant visible levels of fluorescence with a violet-blue background from the excitation light. Current PpIX microscope-based work in mostly high-grade gliomas report sensitivities as low as $20 \%-30 \%$, specificities $>90 \%$, and overall accuracies 70\%-90\%.116,151,156 A key limitation of current clinical microscope-based visualization tools in fluorescence image-guided surgery is both the limited accuracies and qualitative nature of such fluorescence assessments (see Quantitative Versus Qualitative Fluorescence). Sensitivity limitations of microscopebased tools, in part, reside in the geometric constraints of light collection. ${ }^{151}$ The intensity of the collected fluorescence decreases as the distance from the light source and detector increases from the interrogated area. As such, microscope-based tools are intrinsically less sensitive than contact probe technologies by reason of suboptimal light excitation and collection geometries. Clinical fluorescence microscope-based measurements of the qualitative and subjective visible fluorescence are reliant on current technologies that collect fluorescence on a color charge-coupled device (CCD) camera without any subsequent correction for tissue optical properties. As such, current assessments are subjective and unable to distinguish between objectively high or low levels of fluorescence. ${ }^{155}$ Recent developments in advanced microscope-based tools seek to address these limitations, (e.g., use of stronger light excitation, which is limited by how much light tissue can be exposed to before damage occurs; use of more sensitive detectors $\left.{ }^{151}\right)$.

\section{New Technologies for Fluorescence-Guided Surgery}

Additional developments in microscope-based tools that seek to address current limitations with full surgical field of view imaging technologies have been undertaken but are limited. Recent work by Valdés et al. has translated the concepts of quantitative single-point probe fluorescence spectroscopy to full surgical field of view, spectrally-resolved quantitative fluorescence imaging. ${ }^{152,155,157}$ They developed a proof-of-principle system that adapts to current neurosurgical microscopes and collects spectrally resolved data through the native microscope optics unto a standard $\mathrm{CCD}^{155}$ or CMOS (complementary metal-oxide semiconductor) ${ }^{152}$ detector for higher sensitivity. This system used a light correction ratiometric algorithm to derive corrected fluorescence estimates of the tissue PpIX concentrations across the full surgical field of view, noting improved in vivo visualization of human glioma tissue not visualized with standard visible fluorescence clinical systems. ${ }^{152,155,157}$ In the context of the clinical excitement over PpIX and its value as a practical surgical tool, a technological boom has accompanied the field of fluorescence image guidance in neurosurgery, both on 
TABLE 3. Diagnostic performance of ALA-PpIX fluorescence*

\begin{tabular}{ccccccc}
\hline Authors \& Year & Accuracy & Specificity & Sensitivity & NPV & PPV & No. of Pts \\
\hline Stummer et al., 2000 & 90 & 96 & 89 & 50 & 100 & 52 \\
\hline Roberts et al., 2011 & 74 & 71 & 75 & 26 & 95 & 11 \\
\hline Panciani et al., 2012 & 90 & 89 & 91 & 91 & 89 & 23 \\
\hline Yamada et al., 2015 & 89 & 53 & 95 & 69 & 92 & 99 \\
\hline Stummer et al., 2014† & - & - & - & 40 & 96 & 33 \\
\hline Stummer et al., 2014‡ & - & 95 vs 41 & 72 vs 94 & - & - & 13 \\
\hline Valdés et al., 2011§ & 87 & 92 & 84 & 77 & 95 & 14 \\
\hline Valdés et al., 2015ף & 67 & 83 & 58 & 50 & 87 & 6 \\
& 38 & 81 & 21 & 30 & 73 & 12 \\
\hline Valdés et al., 2014** & 84 vs 90 & 100 vs 81 & 76 vs 94 & 67 vs 87 & 100 vs 91 & 10 \\
& 71 & 100 & 61 & 55 & 100 & 15 \\
\hline
\end{tabular}

$\mathrm{NPV}=$ negative predictive value; $\mathrm{PPV}=$ positive predictive value; $\mathrm{Pts}=$ patients.

* Values are percentages unless otherwise indicated.

$\dagger$ Visible fluorescence.

¥ Used a qualitative spectroscopy probe with 2 different thresholds.

$\S$ Mixed histology including low-grade gliomas, high-grade gliomas, meningiomas, and metastases using a quantitative fluorescence probe.

II Used a quantitative probe $(n=6)$ and visible PpIX fluorescence $(n=12)$ for low-grade gliomas.

** Used a quantitative probe ( $n=10$ at 2 different thresholds) and visible PpIX fluorescence $(n=15)$ for meningiomas.

the instrumentation and biomarker development fronts. ${ }^{151}$ Numerous groups, including ours, have developed handheld intraoperative spectroscopy tools for acquiring fluorescence and/or white light spectra, with subsequent data processing algorithms, as a means to more accurately detect tumors. ${ }^{3,16,17,26,31,37,38,46,56,57,80-84,114,115,145,147,148,154,156,157}$ Other groups have developed handheld confocal probes to acquire microscopic images of the tumor microstructure, visualizing microscopic features previously not detected intraoperatively. ${ }^{19,121,122}$ Additional developments innovating neurosurgical microscopes aim to create technologies to improve accuracy by means of detecting additional optical features in tissue ${ }^{155}$ (Tables 1 and 2).

\section{Spectroscopy}

Fluorescence Intensity

Spectroscopy probes have traditionally measured the fluorescence intensity, i.e., the number of emitted photons (y axis) at a specific wavelength ( $x$ axis). The fluorescence intensity of a molecule is a function of the intrinsic fluorophore properties, such as fluorophore concentration, absorbing power, and quantum yield over a range of wavelengths at a specified excitation wavelength. ${ }^{110}$ These systems usually consist of small, fiberoptic-based devices connected to a spectrometer for spectrally resolved data (e.g., fluorescence, reflectance, Raman) collection and light source(s) for illumination. ${ }^{62,110,114,154,156}$ Collected spectral data can then be used in spectral deconvolution and light transport processing algorithms $\mathrm{s}^{114}$ (Figs. 3 and 4).

Other groups have used a spectral processing technique using ratios of 2 fluorescence peaks of PpIX resulting from 2 proposed PpIX states to derive a means for improved detection of low-grade gliomas and infiltrating glioma regions..$^{90}$ In addition, several spectroscopy studies have used the raw fluorescence intensities to demonstrate improved sensitivity for detection of tumor, exploiting tissue autofluorescence or the main PpIX emission peaks. ${ }^{80-84,140}$ Stummer et al. ${ }^{129,135}$ recently used a contact probe spectroscopy system in ALA-PpIX resection, in which they noted a correspondence between the qualitative visible assessments of "strong" and "weak" fluorescence with greater and lower spectroscopic fluorescence intensity signal, respectively, with improved diagnostic capabilities compared with visible fluorescence (Table 3). As expected (i.e., given the improved light delivery-collection geometry), they reported improved detection of

TABLE 4. Diagnostic performance of fluorescein fluorescence*

\begin{tabular}{|c|c|c|c|c|c|c|}
\hline Authors \& Year & Accuracy & Specificity & Sensitivity & NPV & PPV & No. of Pts \\
\hline Murray, 1982 & 89 & 81 & 96 & 95 & 85 & 23 \\
\hline Acerbi et al., 2014 & 92 & 89 & 94 & 94 & 89 & 9 \\
\hline Moore et al., 1948† & 95 & 92 & 97 & 92 & 97 & 46 \\
\hline Rey-Dios et al., 2014ł & 85 & 100 & 79 & 64 & 100 & 6 \\
\hline Diaz et al., 2015 & 85 & 91 & 82 & 71 & 95 & 12 \\
\hline
\end{tabular}



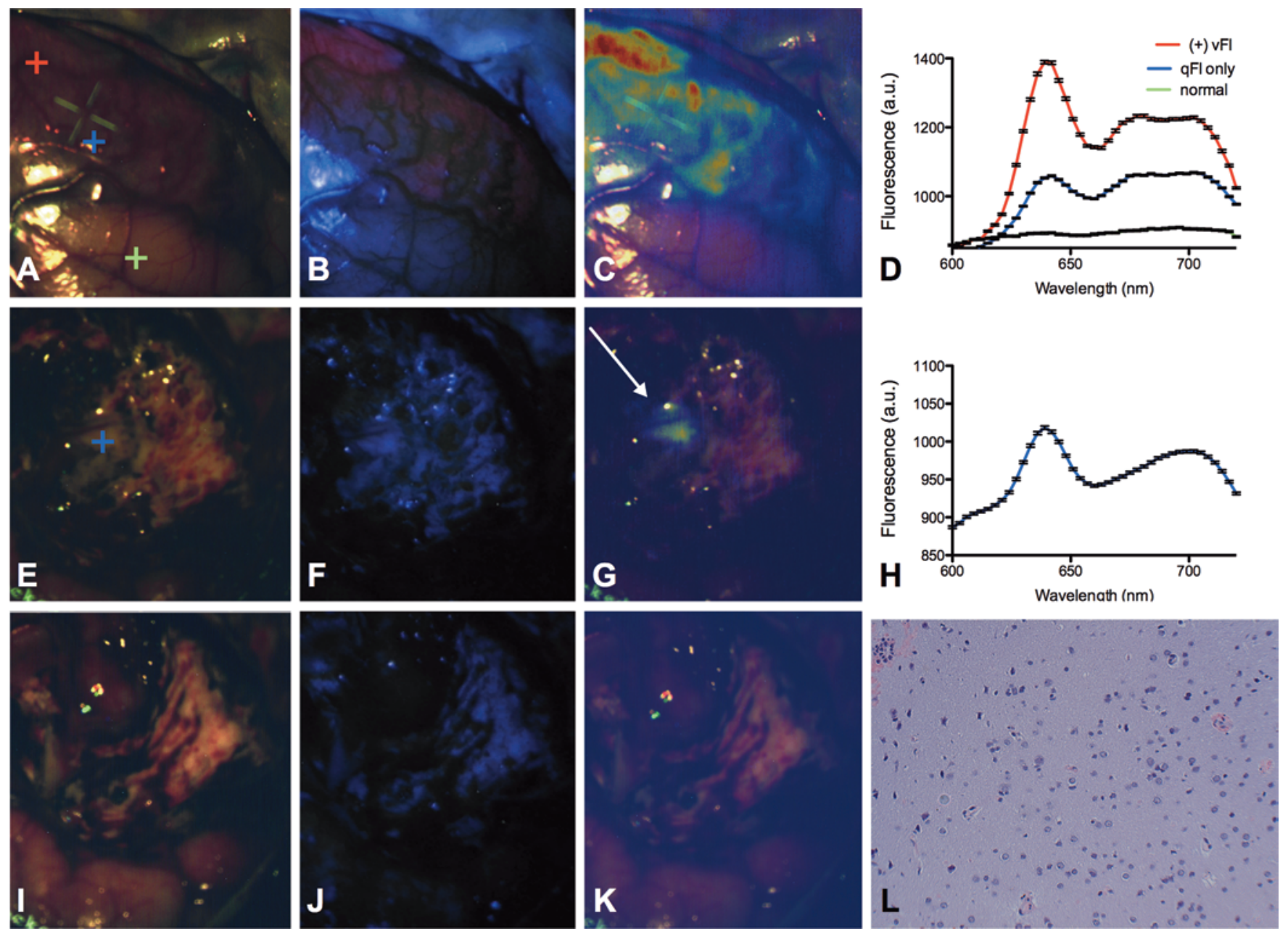

FIG. 3. In vivo quantitative fluorescence imaging in gliomas showing ALA-PpIX fluorescence-guided surgery at the beginning $(A-C)$, middle $(E-G)$, and end of surgery $(I-K)$, with visible fluorescence images $(B, F$, and $J)$ and corresponding quantitative fluorescence images following correction for tissue optical properties noting improved tumor tissue and fluorophore detection (C, $G$, and K). D and H: Spectra showing presence (D) and absence (H) of PpIX signal during and after surgery. L: Histologically confirmed tumor tissue corresponding to location in panel $\mathrm{G}$ with white arrow. Reproduced with permission from Valdés et al: Sci $\operatorname{Rep} 2: 798,2012$.

fluorescence signal that would otherwise have gone undetected with current fluorescence enabled surgical microscopes. Other examples of spectroscopy systems in neurosurgery have been provided by Lin et al. and Toms et al. who used in vivo autofluorescence of tissue coupled with diffuse reflectance measurements in multivariate algorithms to discriminate tumor margins with sensitivities and specificities from $94 \%$ to $100 \%$ and $76 \%$ to $93 \%$, respectively. ${ }^{80-84,140}$ These later approaches use the raw spectral data coupled to machine learning techniques to derive methods for improved tumor tissue classification.

Quantitative Versus Qualitative Fluorescence. Tissue fluorescence is a function of both the absorption and scattering of light that occurs at both the excitation and emission wavelengths, and which itself varies at each spatial location. ${ }^{14,114}$ As such, every assessment of the raw (i.e., "visible") emitted fluorescence is itself subjective, given the attenuating effects of tissue optical properties at each spatial location. Such assessments can lead to inaccurate estimates of accumulated tissue fluorophores given the nonlinear relationships between tissue fluorescence signal and accumulated fluorophores. To make truly quantitative and absolute estimates of the levels of fluorescent biomarker, these effects need to be corrected for by using appropriate light-modeling algorithms. ${ }^{14} \mathrm{~A}$ recent study used a light transport modeling algorithm to correct for the distorting effects of tissue optical properties on the "raw" emitted fluorescence to derive quantitative values of the absolute levels of PpIX in tissues. ${ }^{156}$ Quantitative estimates have been used to demonstrate a significant improvement in diagnostic accuracy using PpIX as a tumor biomarker across multiple different tumor types, including gliomas, meningiomas, and metastases. ${ }^{153,154,156-158} \mathrm{~A}$ recent proof-of-principle study demonstrated that quantitative assessments of PpIX significantly improved detection of low-grade gliomas, such that use of quantitative assessments of PpIX for guidance approximated the diagnostic 


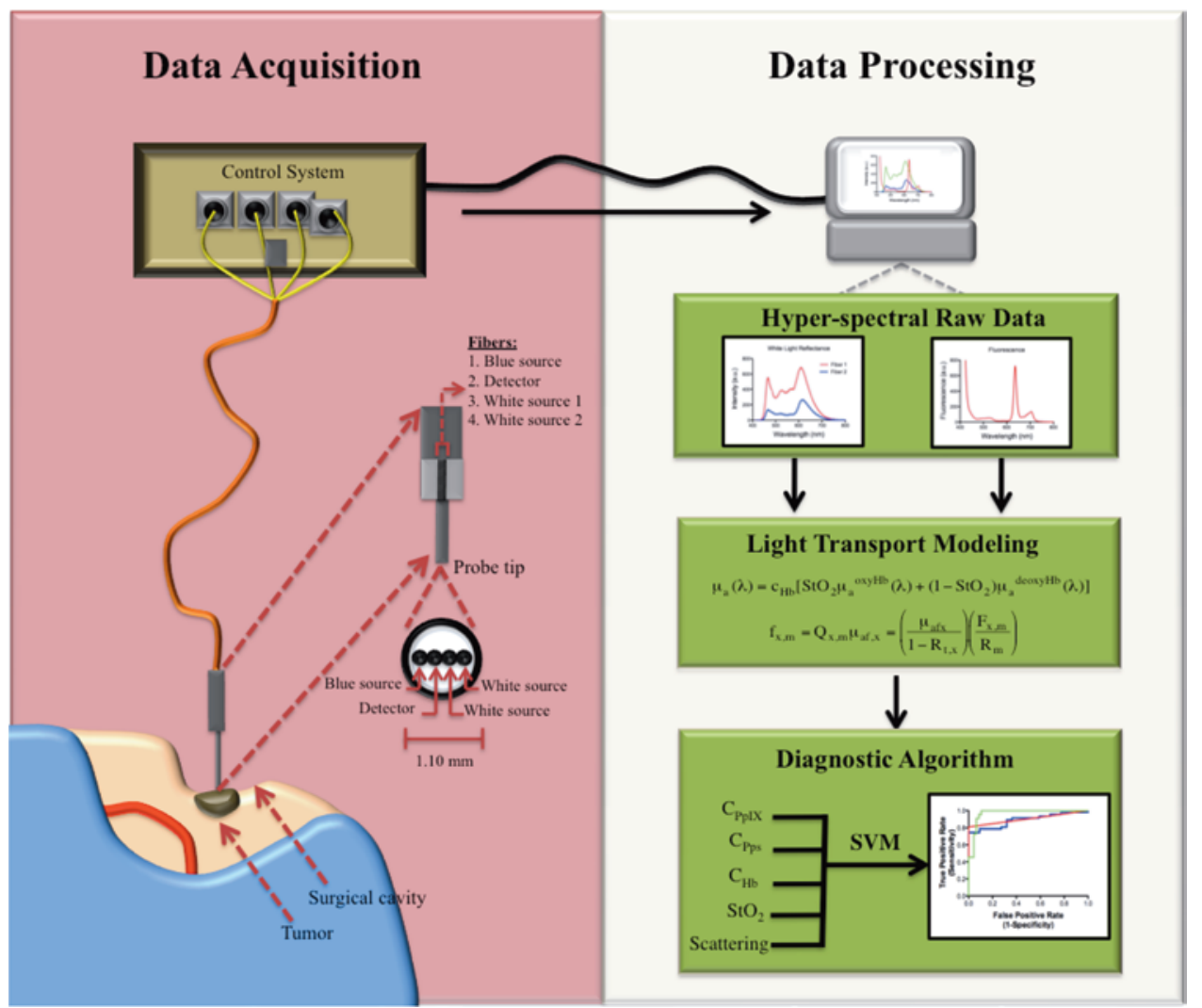

FIG. 4. Diagram of the intraoperative spectroscopy dual fluorescence system and reflectance probe showing the handheld contact probe, collection of dual fluorescence and reflectance signals, advanced light transport processing algorithms, and machine learning technique for tissue classification. Reproduced with permission from Valdés et al: J Biomed Opt 16:116007, 2011.

accuracy of PpIX for low-grade gliomas to that of visible fluorescence for high-grade gliomas. ${ }^{150}$ In addition to the application of model-based algorithms to correct for variations in tissue optical properties, correction techniques using ratiometric approaches have also provided a means for estimating the absolute levels of biomarkers in tissues. ${ }^{157}$ These techniques generally use a ratio of the fluorescence intensity (e.g., at the main emission peak) over the diffuse reflectance intensity (e.g., at the main excitation wavelength) to provide a corrected fluorescence. ${ }^{14}$ An advantage of ratiometric techniques is their ease of implementation, limited assumptions, and low computational power requirements. Yet, a limitation is their need for empirical verification and lack of mathematical and conceptual rigor associated with model-based approaches.

Most of the work to date in fluorescence guidance in neurosurgery uses an approach in which the surgeon visualizes the surgical field and makes assessments on the visibility (or lack thereof) of fluorescence (e.g., pink-red in PpIX or green-yellow with fluorescein sodium). In spectroscopy-based studies, most work to date has also used a qualitative approach, e.g., as in studies by Stummer or Lin, mentioned previously. It is important to compare and contrast between these qualitative approaches and the quantitative spectroscopy studies. Both use spectroscopic, contact probe technologies, which means that they optimize the light delivery and collection efficiency. Spec- troscopy will demonstrate greater sensitivity for detecting lower levels of fluorescence that could not be detected by noncontact microscope-based techniques. One key distinction that the literature does not clarify pertains to the biophotonic nature of the measurements. All spectroscopy techniques 1) collect data in a spectrally resolved manner and 2) provide a "number" of the arbitrary units of light intensity at each wavelength. The collected light is dependent on numerous factors, including 1) the amount of excitation light, 2) levels of tissue fluorescent marker, 3) tissue optical properties, and 4) system specifics. Most spectroscopy studies, despite providing a "number," can be divided into truly quantitative (i.e., those that provide correction for tissue optical properties) or qualitative (i.e., those that only collect spectrally resolved data with arbitrary units of intensity without a means of correcting for tissue optical properties). Thus, qualitative probes provide measurements (e.g., derived diagnostic thresholds) that are dependent on variations in tissue optical properties and are relative to system-specific variations, whereas quantitative tools provide measurements that could be applied independent of system specifics, given that they derive measurements of absolute biomarker levels (Fig. 4). These facts highlight the reality that spectroscopy technologies are undergoing exciting developments, and their implementation has yet to be fully exploited in neurosurgery. 
Fluorescence Lifetime. In addition to fluorescence intensity measurements in spectroscopy, fluorescence lifetime tools have been developed for neurosurgical guidance. ${ }^{15,16,87,170}$ Lifetime is a property of fluorescent molecules that describes the average time electrons spend in an excited state prior to fluorescence emissions and can range in the order of a few nanoseconds to a fraction of a nanosecond. ${ }^{73,110}$ Fluorescence lifetime measurements are denoted as the fluorescence intensity as a function of time at a specified excitation-emission wavelength pair. ${ }^{110}$ Fluorescence lifetime measurements provide an alternative means of evaluating the tissue environment and photoactivity independent of the fluorophore concentrations, ${ }^{114}$ with examples of interrogated endogenous markers including $\mathrm{NAD}(\mathrm{P}) \mathrm{H}$ and flavins. Yong et al. ${ }^{170}$ reported a time-resolved fluorescence spectroscopy approach in a series of low- and high-grade gliomas, with detection of the intensity decay profiles in the $370-$ to $500-\mathrm{nm}$ spectral range. They used the collected data coupled to a linear discriminant analysis (i.e., machine learning) algorithm for diagnostic evaluation, reporting diagnostic accuracies for both low- and high-grade gliomas $>90 \%$. Butte et al. noted a similar study using fluorescence lifetime spectroscopy in low-grade gliomas (100\% sensitivity and 98\% specificity) and high-grade gliomas (47\% sensitivity and 94\% specificity) using a machine learning algorithm applied on fluorescence lifetime-derived variables, e.g., average lifetime of fluorescence emissions, Laguerre coefficients, and emission intensities at optimally determined excitationemission wavelength pairs. The authors attributed this classification discrepancy to the higher variability in the high-grade glioma data compared with those of the lowgrade gliomas. This work demonstrated in vivo implementation of fluorescence lifetime spectroscopy for tumor identification. ${ }^{15,16}$ Fluorescence lifetime techniques provide an additional optical contrast mechanism that takes advantage of differences in the tumor tissue microenvironment and their effect on relevant endogenous or exogenous biomolecules distinct from traditional fluorescence intensity techniques, thus providing the neurosurgeon an additional contrast mechanism and associated tools to implement in the operative theater.

\section{Microscopy}

Intraoperative microscopy (i.e., microscopy imaging with cellular and subcellular spatial resolution and millimeter to micrometer field of views) tools have also been used as a means for intraoperative surgical guidance in the resection of brain tumors (Tables 1 and 2). Unlike spectroscopy technologies, which provide a net averaged measurement at 1 location of the fluorescence intensity (e.g., arbitrary units of fluorescence emissions), a derived biomarker concentration, or lifetime parameters, microscopy techniques provide images of the cellular and subcellular architecture based on various techniques, e.g., fluorescence intensity, lifetime, OCT.

Confocal microscopy or confocal laser endomicroscopy handheld probes provide microstructural, in vivo images with optical sectioning that enables intraoperative visualization of structures at depth, in 3 dimensions, with histological detail, and without the need for exten- sive traditional tissue postprocessing. 27,34,88,91,120,122,123,126,172 Schlosser et al. provided the first report on confocal microscopy in neurosurgery. They examined intraoperatively ex vivo samples from 9 patients with GBM immediately following excision and reported the ability of this technology to identify features such as cell density, mitotic figures, necrosis, and microvascular proliferation. Sanai et al. ${ }^{122}$ used a real-time confocal microscopy fluorescence imaging handheld probe with imaging up to $1000 \times$ magnification in low-grade gliomas under ALA-PpIX conditions. They noted in their series of 10 patients with WHO Grade I and II gliomas the ability to image microscopic fluorescence with strong histopathological correlations, despite the absence of visible, macroscopic fluorescence in areas of tumor infiltration. In another study, ${ }^{27} 50$ patients with both intraaxial and extraaxial tumors were examined after administration of fluorescein sodium using confocal microscopy to identify microscopic features including vascular proliferation, pseudopalisading necrosis, perivascular pseudorosettes, tumor margins, psammoma bodies, and cellular features such as spindle-shaped cells and cellular atypia. The study concluded that confocal microscopy might provide a means for the reliable identification of tumor cells and tumor-brain interfaces. The authors compared their microscopy results with the histopathological analysis and reported diagnostic accuracies of up to $93 \%$.

Similar to fluorescence lifetime spectroscopy, timeresolved fluorescence tools have been used as a means for tissue identification in microscopic imaging. A recent study by Sun et al. ${ }^{137}$ used a fluorescence lifetime imaging microscopy system for intraoperative use in GBM. In this study, the authors used the intrinsic fluorescence emission at $460 \mathrm{~nm}$, corresponding to NADH/NADPH as the fluorescent contrast mechanism, with the hypothesis that tumor versus normal brain would possess varying physiological changes and processes impacting the microenvironment of NADH/NADPH. The authors noted a longer lifetime and weaker fluorescence intensity in GBM versus normal cortex in 3 patients undergoing craniotomy for tumor resection. Their data suggests that GBM tissues have a higher contribution of the protein bound form of NADH/ NADPH compared with normal parenchyma.

\section{Advantages and Disadvantages: Spectroscopy, Microscopy, and Wide-Field Imaging}

We have discussed the 3 major modes of optical guidance to date in the neurosurgical operating room: widefield imaging, spectroscopy, and microscopy (Tables 1 and 2). All 3 techniques have specific advantages and disadvantages. Spectroscopy and microscopy both provide multiple advantages compared with standard microscope visualization by providing 1) improved light excitation and collection geometries, given the direct contact with tissue (or closer distance between tissue and detector) and, thus, associated improved signal-to-noise ratios; and 2) improved spatial resolution at the millimeter (e.g., spectroscopy) to cellular/subcellular micrometer level, capable of resolving cytoarchitectural features (e.g., microscopy). Another advantage of spectroscopy techniques is their ability to provide full fluorescence spectra, which enables implementation of deconvolution algorithms for the extraction 
of multiple spectral features, parameters, and application of sophisticated algorithms. Nevertheless, the main disadvantages of both technologies are that they 1) interrogate a small (e.g., $1 \mathrm{~cm}$ or less) region of tissue; 2 ) cause varying levels of interruptions to the surgical workflow (i.e., the surgeon is required to pause, pick up the instrument, and interrogate tissue); and 3) provide information to the surgeon that may not be intuitive or validated in larger patient cohorts to justify clinical decision making. Widefield imaging microscope-based tools provide several key advantages, which include 1) a view of the full surgical field, 2) immediate intraoperative real-time feedback, and 3) ease of use without interruption to the surgical workflow. The disadvantages include 1) a light excitation and collection geometry, leading to greater light loss at both the excitation and emission wavelengths compared with contact point probes; 2) macroscopic resolution usually limited to the millimeter level, unable to resolve cytoarchitectural details; 3) inability to provide spectrally resolved data by the current state-of-the-art clinical systems; and 4) limited clinical availability, implementation, and validation of technologies for fluorophore and/or chromophore quantitation.

Technological advances abound with the exciting development of new fluorescent biomarkers possessing properties such as multimodality, specified targeting capabilities, and improved depth visualization. For example, preclinical work in nanotechnology applied to neurosurgery seeks to develop novel markers for surgical guidance. Specifically, developments at the interface of nanotechnology and optics are creating multimodal nanoagents that incorporate optical contrast agents such as ICG, ALA, or quantum dots; dual fluorescence guidance plus photodynamic tumoricidal agents with ALA-loaded nanoparticles; optically active agents such as gold nanoshells, which induce tissue welding following absorption of NIR light; enhanced optical agents such as surface enhanced Raman scattering nanoparticles for tumor demarcation; nanotubes for thermoablation; and complex multimodal agents for dual fluorescence imaging and MRI visualization. Developments in the field of nanotechnology are vast and beyond the scope of this review, and the readers are referred to various articles noted here. ${ }^{30,69,89,118,142}$ Developments in nanotechnology, to date, are mostly in the preclinical arena, but advances seek to produce tools for clinical applications in the neurological surgery.

In summary, the use of fluorescence in neurosurgery is young, with a plethora of additional biomarkers and technological innovations under development to improve neurosurgical targeting and guidance. ${ }^{30,69,89,97,103,118,142,151,162,163}$ Fluorescence technologies that improve visualization, enhance speed, increase sensitivity, adapt to new technological advances and the surgical workflow, and integrate with incoming technological developments are all exciting innovations that await application in the neurosurgical operating room.

\section{Intrinsic Optical Signals}

Exploitation of intrinsic optical signals by use of reflected light provides another means of contrast to extract diag- nostic information about tissue structure and physiology. The use of reflected light has been applied in such diverse applications as single-point optical spectroscopy probes, full field of view surgical microscopes, and a conglomerate of contact source-detector pairs used in NIR spectroscopy systems. ${ }^{114,151}$ These tools exploit a well-known phenomenon in biomedical optics. Briefly, when tissue is interrogated with light (e.g., white light in the range of 400-720 $\mathrm{nm}$ ), the reflected white light can be collected either at 1 single wavelength, a group of wavelengths, or in a spectrally resolved manner. The shape (in the case of spectrally resolved acquisition) and the magnitude of the reflected light is a function of the tissue's optical properties (i.e., absorption and scattering). ${ }^{114}$ Tissue optical properties are themselves a function of variations in tissue microstructure (e.g., cell density, nuclear morphology, mitochondrial density), composition (e.g., necrosis, collagen), and physiology (e.g., highly vascularized with varying levels of hemoglobin and oxygen saturation). Thus, reflectance-based technologies exploit our knowledge of light-tissue interactions to measure tissue optical properties and estimate endogenous markers (e.g., tissue chromophores such as oxyand deoxyhemoglobin), thus not requiring administration of any exogenous markers (e.g., ALA, fluorescein, ICG). The use of reflectance in neurosurgical guidance can be divided into various tools, including spectroscopy contact probes, microscopy tools (e.g., OCT), and wide-field imaging microscopes.

\section{Wide-Field Reflectance Imaging}

The development of wide-field (i.e., surgical microscope) imaging technologies exploits intrinsic signals in tissue, such as variations in oxy- and deoxyhemoglobin, and tissue scattering to provide enhanced optical imaging for neurosurgical guidance. Reflectance-based techniques are perfusion-dependent forms of brain mapping that take advantage of the relationship between neuronal activity and local hemodynamic changes, i.e., neurovascular coupling. Neuronal activity causes local hemodynamic and metabolic changes in blood volume, blood flow, glucose use, oxygen consumption, and concentrations of oxy- and deoxyhemoglobin (which serve as a surrogate markers for neuronal activity), which consequently impact light reflectance secondary to associated intrinsic changes in tissue absorption and scattering. ${ }^{104,105}$ This tool exploits the fact that reflected light of different wavelengths undergoes varying levels of absorption and scattering based on tissue physiology, creating maps of blood volume, blood oxygenation, and corresponding tissue physiological changes. As such, reflectance techniques yield functional contrast by measuring changes in endogenous tissue chromophores at the cortical surface ${ }^{45,104,105}$ Haglund et al. in 1992 performed a landmark study using intraoperative endogenous optical signals in patients with seizure disorder who were undergoing cognitive tasks. ${ }^{45,105}$ Haglund et al. developed a wide-field reflectance imaging technique that was applied to eloquent cortex to detect intrinsic optical signals for tissue differentiation in epileptogenic brain. The authors noted an increase in optical changes as the magnitude of intensity and duration of stimulation-evoked epileptiform after discharges increased. ${ }^{43,45,86}$ Since this initial work, 
intraoperative reflectance has also been used to interrogate the functional topography and plasticity of sensory and language cortices. Cannestra et al. provided an elegant report on topographical specificity by analyzing intraoperative reflectance signals of the somatosensory cortex following contralateral stimulation (e.g., face, thumb, index). The authors noted a non-overlapping cortical brain mass colocalizing with electrocortical stimulation mapping and evoked potentials. ${ }^{18}$ Optical signals in Broca's and Wernicke's areas were demonstrated by both Haglund et al. ${ }^{45}$ and Cannestra et al. ${ }^{19}$ For example, in the latter study, patients undergoing neurosurgical resection were noted to display a topographical specificity dependent on language tasks. Additional studies in patients with tumors, arteriovenous malformations, cavernous malformations, and epileptogenic foci evaluated such aspects as Spanish and English maps, correlation between blood oxygen level-dependent and optical imaging venous maps, hand representation, and delineation of functional borders. ${ }^{106}$

These tools use raw changes in optical signals (e.g., the changes in reflectance signal at the isosbestic points of oxyand deoxyhemoglobin, i.e., $550 \mathrm{~nm}$ and $570 \mathrm{~nm}$, respective$\left.1 y^{105}\right)$. As such, they are similar to nonquantitative spectroscopy studies noting relative changes in optical signal (i.e., signal intensity changes) without explicit measurement of optical markers (i.e., without subsequent data processing in light transport models to quantitate absolute chromophore biomarkers such as oxy- and deoxyhemoglobin levels). New developments such as spatial frequency domain imaging and single snapshot optical properties imaging address this limitation by utilizing patterned illumination coupled with light transport algorithms to derive the absolute tissue optical properties, $40,41,66,161,168$ but are currently not yet implemented in clinical neurosurgical interventions.

Reflectance tools rely on the biophotonics principle of differential light interaction with tissue as a function of tissue physiology and structure and, with application of modeling algorithms, can be used to extract relevant biomarkers for surgical guidance. Exploitation of intrinsic biomarkers has not gained wide application or implementation in neurosurgery as have exogenous markers in fluorescence-guided surgery (e.g., ALA-PpIX). In part, this is due to the issues of specificity, sensitivity, correlated signal-to-noise considerations, and interruptions to surgical workflow. A major limitation to implementation of reflectance imaging has been the difficulty in separating motion and vascular-related noise due to cortical movement during imaging, which can introduce reflectance changes independent of neuronal activity. Such limitations can be addressed, for example, with advanced image processing and registration techniques. ${ }^{105}$ With improved light excitation and collection technologies, computational power, and algorithms (e.g., multithreaded implementation of machine learning algorithms for development of high accuracy classification or image registrations algorithms), such limitations are becoming obsolete in delaying clinical implementation of reflectance tools.

\section{Laser Speckle Contrast Imaging}

Another optical tool exploiting a form of reflected light is laser speckle contrast imaging (LSCI), which has been used intraoperatively for the assessment of physiological states, specifically for cerebral blood flow (CBF) monitoring. ${ }^{60,100,113}$ LSCI uses intrinsic tissue contrast by applying a coherent light source (i.e., laser) to measure spatial speckle contrast and quantify the local spatial variance of the speckle pattern from decorrelation of the coherent light in the presence of blood flow. These images can be converted into a quantitative measure of blood flow. Richards et al. ${ }^{113}$ report an application of intraoperative LSCI for assessment of CBF during neurosurgical guidance with optimization of signal, correction for motion distortion and associated pulsatile artifacts, and derivation of images of cerebral vasculature and blood flow. This technique provides another means of vascular imaging and extraction of more quantitative parameters independent of exogenous markers (e.g., ICG, fluorescein, iodinated contrast agent).

\section{Optical Coherence Tomography}

OCT is an optical imaging modality that detects singly backscattered or back-reflected light to reconstruct depthresolved, tomographic images of biological tissues with micrometer spatial resolution at millimeter depths. ${ }^{7,11,13,36}$ OCT is analogous to ultrasound in that reflections of light (rather than sound) are detected. ${ }^{11}$ Backscattered light in OCT is a function of the endogenous tissue optical properties, and, since tissues are highly scattering, OCT is mostly dependent on optical scattering for imaging contrast. ${ }^{36}$

OCT detection has been implemented across various disciplines including ophthalmology, cardiology, dermatology, urology, dentistry, and in various modes including microscopes, fiberoptic catheters, handheld probes, and endoscopes. ${ }^{10,13,36}$ Boppart et al. ${ }^{12}$ reported on an ex vivo use of OCT for the identification of metastatic melanoma in human brain. Bizheva et al. reported one of the first studies on ex vivo human tissues (formalin fixed or fresh tissue) to use OCT to distinguish between normal brain and brain tumors including meningioma, ganglioglioma, and glioblastoma. ${ }^{7,9}$ The authors reported visualization of fine morphological details such as nuclei, cysts, microvasculature, and microcalcifications. Jafri et al. ${ }^{52}$ used a catheterbased OCT system in 25 postmortem human brains for the purpose of identifying and resolving structures of interest for deep brain stimulation (e.g., within the globus pallidus, subthalamic nucleus, and substantia nigra) such as microvasculature and gray-white matter junction or even pathological morphologies (e.g., vacuoles in transmissible spongiform encephalopathies). Assayag et al. ${ }^{4}$ applied a full field of view OCT imaging system, which enabled high spatial resolution of $1.5 \times 1.5 \times 1.0 \mu \mathrm{m}^{3}$ to depths of approximately $200-300 \mu \mathrm{m}$ over a $1-\mathrm{cm}^{2}$ field of view and 5 -minute acquisition times. The authors examined freshly resected brain tissue specimens in 18 patients with diffuse gliomas (WHO Grades II and III), meningiomas, and metastases. The authors reported the ability to resolve fine structural features including myelinated axon fibers, neuronal cell bodies, vasculature, hippocampal regions (e.g., CA1, CA4), granule and pyramidal neurons, cerebellar folia, and psammoma bodies. The authors report that in their study they were unable to distinguish regions of low cell density (less than $20 \%$ ), diffusely infiltrative low-grade gliomas. A recent, elegant study by Kut et al. ${ }^{72}$ reports the 
use of OCT on ex vivo human tissue samples of 32 patients with WHO Grade II to IV gliomas. A substantial contribution by the authors is the performance of a diagnostic analysis to derive an attenuation threshold to distinguish tissues with high sensitivity and specificity, and create OCT images discriminating between normal and tumor tissues. The authors report specificities and sensitivities of $100 \%$ and $92 \%$ for high-grade patients and $80 \%$ and $100 \%$ for low-grade patients, respectively.

In vivo applications of OCT in neurosurgery are limited. One study involving 9 patients (6 GBM, 2 recurrent GBM, and 1 anaplastic astrocytoma) used a noncontact OCT system at various points during the resection to image surgical planes in vivo, with subsequent biopsy acquisition and histopathological examination. The authors reported distortions in tissue microstructure and light attenuation profiles detected by OCT in regions of tumor infiltration. In summary, the use of OCT in the neurosurgical operating room is mostly limited to ex vivo applications. Nevertheless, there is exciting potential for growth of this modality as an in vivo surgical adjunct given its ability to exploit intrinsic optical contrast, provide micrometer spatial resolution, and detect features at millimeter depths.

\section{Spectroscopy}

Optical spectroscopy probes have used either the diffuse reflectance or a combination of the diffuse reflectance and tissue fluorescence from endogenous (e.g., NADPH), exogenous (e.g., fluorescein), or exogenously induced fluorophores (e.g., PpIX). ${ }^{103,114,151}$ Work by Lin et al. at Vanderbilt provides one of the largest experiences in neurosurgery using raw diffuse reflectance intraoperatively. Their group collected the fluorescence and diffuse reflectance spectral peaks (e.g., 460-nm fluorescence emission and 460- and 625-nm reflectance) across a range of brain tumors and developed discrimination algorithms with reported sensitivities and specificities of up to $96 \%$ and $93 \%$, respectively. ${ }^{84}$ In an in vivo report involving 26 patients with brain tumors, the authors described a similar use of an intraoperative spectroscopy probe using both autofluorescence and diffuse reflectance in a 2-step discrimination algorithm with sensitivity and specificity of $100 \%$ and $76 \%$, respectively. ${ }^{83}$ In a more recent study of 400 spectra in 12 pediatric patients using only the diffuse reflectance spectra, investigators reported discrimination between normal cortex and brain tumor tissue. ${ }^{82}$ Additional reports used raw fluorescence and/or diffuse reflectance spectral information for tissue discrimination in radiation necrosis $^{80,139-141}$ or neoplastic and epileptogenic pediatric brain. ${ }^{81}$ A limitation of these studies rests on the fact that they use raw spectral information. As such, they do not provide explicit quantitation of relevant biomarkers (e.g., oxy- and deoxyhemoglobin) since they measure raw fluorescence and/or reflectance information and optical signal intensity. Thus, interpretation of the biological correlates with respect to the optical data are not intuitive for the surgeon.

A recent proof of principle study addressed these challenges using a combined fluorescence and reflectance approach with a quantitative spectroscopy system. ${ }^{154}$ Both the fluorescence and diffuse reflectance in tissue were collected and coupled to a light transport algorithm of the diffuse reflectance to estimate the absolute tissue optical properties. Tissue optical properties are a function of the absolute levels of tissue biomarkers such as hemoglobin concentration, oxygen saturation, and architectural markers such as scattering. This information was used to correct the emitted fluorescence and extract absolute levels of PpIX. A classification, machine learning algorithm was developed using the derived biological markers, with reported accuracies of up to $94 \%$ across a broad range of glioma histologies including low- and high-grade gliomas. ${ }^{154}$ This preliminary study highlights the feasibility and value of developing biologically and physiologically intuitive technologies that provide the surgeon with information (i.e., known biomarkers) of physiological relevance.

In summary, reflectance-based technologies exploit variations in intrinsic tissue contrast that arise from histopathological and pathophysiological changes. Reflectance-based technologies have the main advantage of not requiring exogenous contrast administration. Despite this advantage, as noted above, concerns with tissue sensitivity and specificity, as well as technological limitations impacting signal-to-noise, have limited the ability of diffuse reflectance technologies to assume a stronger role in the neurosurgical operative theater. The tools available to the neurosurgeon have yet to be fully developed, and with improved algorithms and hardware a new era in the use of reflectance techniques approaches.

\section{Raman}

Raman is a label-free technique that does not require exogenous agents but rather is able to measure the "vibrational fingerprint" of cells and tissues. 5,21,28,35,53-55,59,64,67,77,117,143,173 Raman is based on the inelastic scattering of photons upon interaction with tissue. Tissue is interrogated with light, and a small amount of this incident light at a specific wavelength is scattered to different wavelengths. The incident and scattered light are a function of the vibrational energies of molecular bonds in tissues, thus providing a way to differentiate cellular structures based on the chemical specificity of lipids, proteins, and DNA. ${ }^{28}$ A major limitation of Raman is its intrinsically weak signals (1 in approximately $10^{7}$ scattered photons is Raman shifted). As such, various techniques have been developed to improve Raman detection sensitivity, including resonance Raman; surface-enhanced Raman scattering (SERS), which can be used to enhance signals from Raman molecules by a factor of $10^{7}-10^{10}$; and coherent Raman. ${ }^{47}$

The use of Raman in neurosurgery traces a more recent history, with most studies performed on ex vivo specimens. Ex vivo studies using Raman spectroscopy in pediatric brain tumor samples with a support vector machines discrimination algorithm reported $>90 \%$ accuracies for tissue identification. ${ }^{77}$ A recent study by Jermyn et al. developed an in vivo intraoperative handheld Raman spectroscopy probe reporting 0.2 -second acquisition time, sampling depth of $1 \mathrm{~mm}$, and sensitivity and specificity of $>90 \%$ for gliomas in a cohort of 17 patients. ${ }^{21,53}$ In their study, the authors sampled the range from 381 to $1653 \mathrm{~cm}^{-}$ ${ }^{1}$, noting differences in the lipid bands (700-1142 $\mathrm{cm}^{-1}$ ), nucleic acid bands (1540-1645 $\left.\mathrm{cm}^{-1}\right)$, and the breathing 

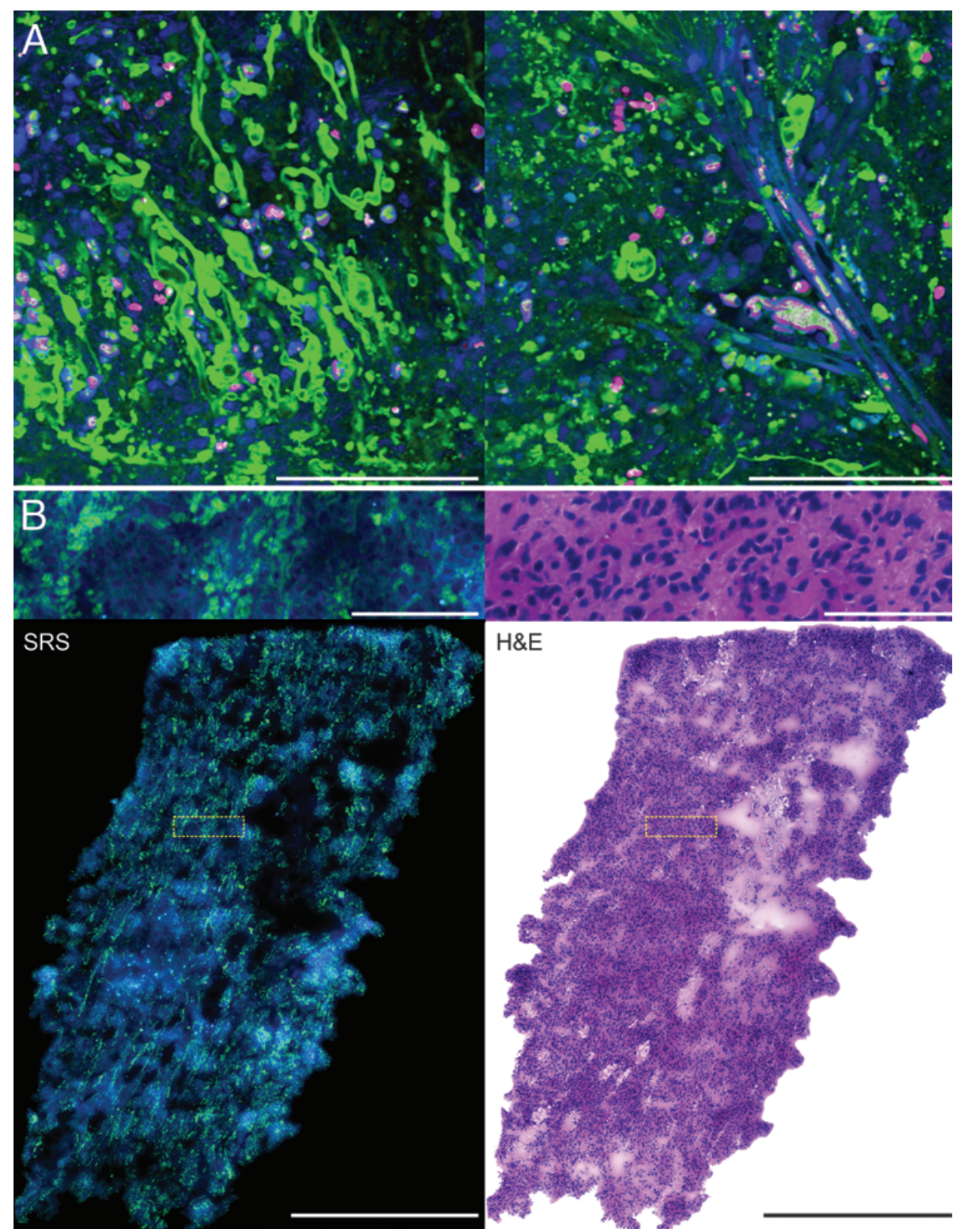

FIG. 5. Images showing label-free brain tumor imaging with stimulated Raman scattering (SRS) microscopy. A: SRS imaging of lipid (at $2854 \mathrm{~cm}^{-1}$ ), protein (at $2930 \mathrm{~cm}^{-1}$ ), and red blood cells (at $2800 \mathrm{~cm}^{-1}$ ) of a fresh brain tumor tissue from an oligodendroglioma surgical case (WHO Grade II). Myelin fibers were visualized based on the strong lipid signals (green), cell nuclei and blood vessels were visualized mainly due to their strong protein signals (blue), and red blood cells were imaged based on the non-

Raman 2-color 2-photon absorption signals (magenta). B: SRS and H \& E imaging of the same frozen section of an entire tissue specimen from an oligoastrocytoma surgical case. Lipid/protein mapping of the brain tumor tissue with SRS provided very similar information to $\mathrm{H} \& \mathrm{E}$ staining with cell-to-cell correlation (B lower zoom images), demonstrating that SRS imaging could be used for label-free neuropathology. Scale bars $=100 \mu \mathrm{m}$ (A and B upper), $1 \mathrm{~mm}$ (B lower). Brain tissue samples were obtained under an institutional review board-approved protocol from the Brigham and Women's Hospital and Dana-Farber Cancer Institute Neurooncology Program Biorepository collection.

mode of phenylalanine in proteins $\left(1005 \mathrm{~cm}^{-1}\right)$. This later study is key in noting intraoperative in situ implementation of Raman techniques for surgical guidance, with minimal disruption to the surgical workflow and excellent diagnostic capabilities (Fig. 5). Given the large amount of spectral information, Raman-based studies have mostly used machine learning algorithms to classify tissue into normal versus tumor categories. ${ }^{21,53-55}$

Coherent anti-Stokes Raman scattering (CARS) microscopy is a nonlinear variant of Raman techniques, with much stronger signals than that of conventional Raman spectroscopy. CARS at $2850 \mathrm{~cm}^{-1}\left(\mathrm{CH}_{2}\right.$ stretching 
vibration) was used to image lipids in brain. For example, Uckermann et al. reported on 6 patients with GBM using CARS microscopy, with decreased CARS signal in tumors versus normal tissue. ${ }^{143}$ Romeike et al. ${ }^{117}$ elaborated on a combined use of 2-photon fluorescence imaging of tissue autofluorescence (e.g., elastin, NAD $[\mathrm{P}] \mathrm{H}$ or keratin) and CARS (e.g., lipids) microscopy for imaging of ex vivo brain tumor samples and extraction of parameters such as cell density, nucleus to cytoplasm ratio, and nuclear size and shape.

Ji et al..$^{54,55}$ report the use of stimulated Raman scattering (SRS) microscopy for imaging of tissues based on their Raman contrasts. They use a 2-color SRS imaging method to extract specifically lipid and protein signals, such that high lipid content tissue (e.g., white matter) will predominantly appear as 1 color (e.g., green) and high protein content structures as another color (e.g., blue). This work highlights the ability of SRS to image axons, cells, protein/lipid ratios, and tissue histoarchitectural structures. The authors analyzed 14 biopsies from 3 patients undergoing anterior temporal lobectomy and compared these with 39 biopsies from 19 patients with central nervous system tumors and compared SRS and hematoxylin and eosin (H \& E) staining results, noting excellent agreement (kappa $>80$ ). They then developed a classifier algorithm applied to human samples to automatically distinguish tissues with varying levels of tumor infiltration with sensitivity and specificity for tumor and nontumor infiltrated brain of $97.5 \%$ and $98.5 \%$, respectively. Both Ji et al. and Jermyn et al. note that despite the intrinsic low sensitivity constraints of Raman techniques, with appropriate technological optimization, they can detect tissues with varying degrees of tumor infiltration. Figure 5 shows our SRS imaging of both fresh and frozen human brain tumor tissue with lipid, protein, and blood contrasts. Myelin fibers, cell nuclei, blood vessels, and red blood cells were visualized with both high signal-to-noise ratio and subcellular spatial resolution (Fig. 5A), with strong correlation between SRS and $\mathrm{H} \& \mathrm{E}$ (Fig. 5B). This highlights an example of how SRS imaging could be used for pathological diagnosis of brain tumors.

Implementation of Raman-based technologies in neurosurgery is a new innovation. Most current studies were performed using ex vivo tissue, with only limited experience using Raman in vivo and in situ for brain tumor detection. A major limitation of Raman is the intrinsic low signal, but recent technical developments have addressed this concern by providing high quality data within acceptable timeframes and adequate signals. Future work will seek to further exploit the Raman effect for tissue discrimination and optical guidance, including transition from ex vivo tools to handheld probes with larger field of view tools.

\section{Conclusions}

Here we present a survey of optical tools in clinical use for neurosurgical guidance. This paper seeks to provide the audience a key sampling of the major technologies for optical guidance currently available for clinical use to the neurosurgeon as he/she seeks to enhance their armamentarium. We provide an overview of major biomarkers (e.g., autofluorescence, PpIX, fluorescein), contrast mechanisms (e.g., steady-state vs time-resolved fluorescence, reflectance, Raman), and technologies (e.g., spectroscopy probes, confocal microscopes, and surgical microscopes) available to the neurosurgeon at this time. This report does not seek to provide an exhaustive overview of all studies and results using fluorescence, reflectance, or Ramanbased tools in the neurosurgical operating room. Also, this report is not intended to provide a description of the plethora of preclinical tools and agents used in animal models or preclinical studies. In the References section we provide a list of important primary and review literature that delve into the minutiae on points of possible interest and further education for the reader such as ALA-PpIX biology ${ }^{20}$ or principles of optical spectroscopy. ${ }^{114}$ The field of biomedical optics, with development of optical instrumentation and biomarkers, is a rich and highly prolific field, and here we present some of the clinical tools and markers available in the present day neurosurgical operating room.

\section{References}

1. Aalders MC, Sterenborg DJ, van der Vange N: Fluorescein angiography for the detection of metastases of ovarian tumor in the abdominal cavity, a feasibility pilot. Lasers Surg Med 35:349-353, 2004

2. Acerbi F, Broggi M, Eoli M, Anghileri E, Cavallo C, Boffano C, et al: Is fluorescein-guided technique able to help in resection of high-grade gliomas? Neurosurg Focus 36(2):E5, 2014

3. Andersson-Engels S, Johansson J, Svanberg K, Svanberg $\mathrm{S}$ : Fluorescence imaging and point measurements of tissue: applications to the demarcation of malignant tumors and atherosclerotic lesions from normal tissue. Photochem Photobiol 53:807-814, 1991

4. Assayag O, Grieve K, Devaux B, Harms F, Pallud J, Chretien F, et al: Imaging of non-tumorous and tumorous human brain tissues with full-field optical coherence tomography. Neuroimage Clin 2:549-557, 2013

5. Bentley JN, Ji M, Xie XS, Orringer DA: Real-time image guidance for brain tumor surgery through stimulated Raman scattering microscopy. Expert Rev Anticancer Ther 14:359-361, 2014

6. Berg K, Anholt H, Bech O, Moan J: The influence of iron chelators on the accumulation of protoporphyrin IX in 5-aminolaevulinic acid-treated cells. Br J Cancer 74:688 697, 1996

7. Bizheva K, Unterhuber A, Hermann B, Povazay B, Sattmann H, Fercher AF, et al: Imaging ex vivo healthy and pathological human brain tissue with ultra-high-resolution optical coherence tomography. J Biomed Opt 10:11006, 2005

8. Bogaards A, Varma A, Collens SP, Lin A, Giles A, Yang VX, et al: Increased brain tumor resection using fluorescence image guidance in a preclinical model. Lasers Surg Med 35:181-190, 2004

9. Böhringer HJ, Boller D, Leppert J, Knopp U, Lankenau E, Reusche E, et al: Time-domain and spectral-domain optical coherence tomography in the analysis of brain tumor tissue. Lasers Surg Med 38:588-597, 2006

10. Böhringer HJ, Lankenau E, Rohde V, Hüttmann G, Giese A: Optical coherence tomography for experimental neuroendoscopy. Minim Invasive Neurosurg 49:269-275, 2006

11. Böhringer HJ, Lankenau E, Stellmacher F, Reusche E, Hüttmann G, Giese A: Imaging of human brain tumor tissue by near-infrared laser coherence tomography. Acta Neurochir (Wien) 151:507-517, 2009 
12. Boppart SA, Brezinski ME, Pitris C, Fujimoto JG: Optical coherence tomography for neurosurgical imaging of human intracortical melanoma. Neurosurgery 43:834-841, 1998

13. Boustany NN, Boppart SA, Backman V: Microscopic imaging and spectroscopy with scattered light. Annu Rev Biomed Eng 12:285-314, 2010

14. Bradley RS, Thorniley MS: A review of attenuation correction techniques for tissue fluorescence. J R Soc Interface 3:1-13, 2006

15. Butte PV, Fang Q, Jo JA, Yong WH, Pikul BK, Black KL, et al: Intraoperative delineation of primary brain tumors using time-resolved fluorescence spectroscopy. J Biomed Opt 15:027008, 2010

16. Butte PV, Mamelak AN, Nuno M, Bannykh SI, Black KL, Marcu L: Fluorescence lifetime spectroscopy for guided therapy of brain tumors. Neuroimage 54 Suppl 1:S125S135, 2011

17. Butte PV, Pikul BK, Hever A, Yong WH, Black KL, Marcu $\mathrm{L}$ : Diagnosis of meningioma by time-resolved fluorescence spectroscopy. J Biomed Opt 10:064026, 2005

18. Cannestra AF, Black KL, Martin NA, Cloughesy T, Burton JS, Rubinstein E, et al: Topographical and temporal specificity of human intraoperative optical intrinsic signals. Neuroreport 9:2557-2563, 1998

19. Cannestra AF, Bookheimer SY, Pouratian N, O'Farrell A, Sicotte N, Martin NA, et al: Temporal and topographical characterization of language cortices using intraoperative optical intrinsic signals. Neuroimage 12:41-54, 2000

20. Collaud S, Juzeniene A, Moan J, Lange N: On the selectivity of 5-aminolevulinic acid-induced protoporphyrin IX formation. Curr Med Chem Anticancer Agents 4:301-316, 2004

21. Desroches J, Jermyn M, Mok K, Lemieux-Leduc C, Mercier J, St-Arnaud K, et al: Characterization of a Raman spectroscopy probe system for intraoperative brain tissue classification. Biomed Opt Express 6:2380-2397, 2015

22. Diaz RJ, Dios RR, Hattab EM, Burrell K, Rakopoulos P, Sabha N, et al: Study of the biodistribution of fluorescein in glioma-infiltrated mouse brain and histopathological correlation of intraoperative findings in high-grade gliomas resected under fluorescein fluorescence guidance. $\mathbf{J}$ Neurosurg 122:1360-1369, 2015

23. Diez Valle R, Tejada Solis S: Answer to: "sodium fluorescein-guided resection under the YELLOW 560-nm surgical microscope filter in malignant brain tumor surgery-a feasibility study" (April 2013, volume 155, issue 4, pp 693-69). Acta Neurochir (Wien) 155:1319-1320, 2013 (Letter)

24. Dolmans DE, Fukumura D, Jain RK: Photodynamic therapy for cancer. Nat Rev Cancer 3:380-387, 2003

25. Dysart JS, Patterson MS: Photobleaching kinetics, photoproduct formation, and dose estimation during ALA induced PpIX PDT of MLL cells under well oxygenated and hypoxic conditions. Photochem Photobiol Sci 5:73-81, 2006

26. Eljamel MS, Leese G, Moseley H: Intraoperative optical identification of pituitary adenomas. J Neurooncol 92:417421, 2009

27. Eschbacher J, Martirosyan NL, Nakaji P, Sanai N, Preul $\mathrm{MC}$, Smith KA, et al: In vivo intraoperative confocal microscopy for real-time histopathological imaging of brain tumors. J Neurosurg 116:854-860, 2012

28. Farooq H, Genis H, Alarcon J, Vuong B, Jivraj J, Yang VX, et al: High-resolution imaging of the central nervous system: how novel imaging methods combined with navigation strategies will advance patient care. Prog Brain Res 218:55-78, 2015

29. Ferroli P, Acerbi F, Albanese E, Tringali G, Broggi M, Franzini A, et al: Application of intraoperative indocyanine green angiography for CNS tumors: results on the first 100 cases. Acta Neurochir Suppl 109:251-257, 2011
30. Ferroni L, Gardin C, Della Puppa A, Sivolella S, Brunello G, Scienza R, et al: Novel nanotechnologies for brain cancer therapeutics and imaging. J Biomed Nanotechnol 11:1899-1912, 2015

31. Fitzmaurice M: Principles and pitfalls of diagnostic test development: implications for spectroscopic tissue diagnosis. J Biomed Opt 5:119-130, 2000

32. Floeth FW, Sabel M, Ewelt C, Stummer W, Felsberg J, Reifenberger $\mathrm{G}$, et al: Comparison of ${ }^{18} \mathrm{~F}$-FET PET and 5-ALA fluorescence in cerebral gliomas. Eur J Nucl Med Mol Imaging 38:731-741, 2011

33. Floeth FW, Stummer W: The value of metabolic imaging in diagnosis and resection of cerebral gliomas. Nat Clin Pract Neurol 1:62-63, 2005

34. Foersch S, Heimann A, Ayyad A, Spoden GA, Florin L, Mpoukouvalas K, et al: Confocal laser endomicroscopy for diagnosis and histomorphologic imaging of brain tumors in vivo. PLoS One 7:e41760, 2012

35. Freudiger CW, Pfannl R, Orringer DA, Saar BG, Ji M, Zeng Q, et al: Multicolored stain-free histopathology with coherent Raman imaging. Lab Invest 92:1492-1502, 2012 [Erratum in Lab Invest 92:1661, 2012]

36. Fujimoto JG, Pitris C, Boppart SA, Brezinski ME: Optical coherence tomography: an emerging technology for biomedical imaging and optical biopsy. Neoplasia 2:9-25, 2000

37. Gardner CM, Jacques SL, Welch AJ: Fluorescence spectroscopy of tissue: recovery of intrinsic fluorescence from measured fluorescence. Appl Opt 35:1780-1792, 1996

38. Gebhart SC, Lin WC, Mahadevan-Jansen A: In vitro determination of normal and neoplastic human brain tissue optical properties using inverse adding-doubling. Phys Med Biol 51:2011-2027, 2006

39. Gibson SL, Havens JJ, Foster TH, Hilf R: Time-dependent intracellular accumulation of delta-aminolevulinic acid, induction of porphyrin synthesis and subsequent phototoxicity. Photochem Photobiol 65:416-421, 1997

40. Gioux S, Mazhar A, Cuccia DJ, Durkin AJ, Tromberg BJ, Frangioni JV: Three-dimensional surface profile intensity correction for spatially modulated imaging. J Biomed Opt 14:034045, 2009

41. Gioux S, Mazhar A, Lee BT, Lin SJ, Tobias AM, Cuccia DJ, et al: First-in-human pilot study of a spatial frequency domain oxygenation imaging system. J Biomed Opt 16:086015, 2011

42. Hadjipanayis CG, Widhalm G, Stummer W: What is the surgical benefit of utilizing 5-aminolevulinic acid for fluorescence-guided surgery of malignant gliomas? Neurosurgery 77:663-673, 2015

43. Haglund MM: Intraoperative optical imaging of epileptiform and functional activity. Neurosurg Clin N Am 8:413420, 1997

44. Haglund MM, Berger MS, Hochman DW: Enhanced optical imaging of human gliomas and tumor margins. Neurosurgery 38:308-317, 1996

45. Haglund MM, Ojemann GA, Hochman DW: Optical imaging of epileptiform and functional activity in human cerebral cortex. Nature 358:668-671, 1992

46. Haj-Hosseini N, Richter J, Andersson-Engels S, Wårdell K: Optical touch pointer for fluorescence guided glioblastoma resection using 5-aminolevulinic acid. Lasers Surg Med 42:9-14, 2010

47. Harmsen S, Huang R, Wall MA, Karabeber H, Samii JM, Spaliviero M, et al: Surface-enhanced resonance Raman scattering nanostars for high-precision cancer imaging. Sci Transl Med 7:271ra7, 2015

48. Hopper C: Photodynamic therapy: a clinical reality in the treatment of cancer. Lancet Oncol 1:212-219, 2000

49. Idoate MA, Díez Valle R, Echeveste J, Tejada S: Pathological characterization of the glioblastoma border as 
shown during surgery using 5-aminolevulinic acid-induced fluorescence. Neuropathology 31:575-582, 2011

50. Iinuma S, Farshi SS, Ortel B, Hasan T: A mechanistic study of cellular photodestruction with 5-aminolaevulinic acidinduced porphyrin. Br J Cancer 70:21-28, 1994

51. Ishihara R, Katayama Y, Watanabe T, Yoshino A, Fukushima T, Sakatani K: Quantitative spectroscopic analysis of 5-aminolevulinic acid-induced protoporphyrin IX fluorescence intensity in diffusely infiltrating astrocytomas. Neurol Med Chir (Tokyo) 47:53-57, 2007

52. Jafri MS, Farhang S, Tang RS, Desai N, Fishman PS, Rohwer RG, et al: Optical coherence tomography in the diagnosis and treatment of neurological disorders. J Biomed Opt 10:051603, 2005

53. Jermyn M, Mok K, Mercier J, Desroches J, Pichette J, Saint-Arnaud K, et al: Intraoperative brain cancer detection with Raman spectroscopy in humans. Sci Transl Med 7:274ra19, 2015

54. Ji M, Lewis S, Camelo-Piragua S, Ramkissoon SH, Snuderl $\mathrm{M}$, Venneti S, et al: Detection of human brain tumor infiltration with quantitative stimulated Raman scattering microscopy. Sci Transl Med 7:309ra163, 2015

55. Ji M, Orringer DA, Freudiger CW, Ramkissoon S, Liu X, Lau D, et al: Rapid, label-free detection of brain tumors with stimulated Raman scattering microscopy. Sci Transl Med 5:201ra119, 2013

56. Johansson A, Palte G, Schnell O, Tonn JC, Herms J, Stepp $\mathrm{H}$ : 5-Aminolevulinic acid-induced protoporphyrin IX levels in tissue of human malignant brain tumors. Photochem Photobiol 86: 1373-1378, 2010

57. Johansson JD: Spectroscopic method for determination of the absorption coefficient in brain tissue. J Biomed Opt 15:057005, 2010

58. Kabuto M, Kubota T, Kobayashi H, Nakagawa T, Ishii H, Takeuchi H, et al: Experimental and clinical study of detection of glioma at surgery using fluorescent imaging by a surgical microscope after fluorescein administration. Neurol Res 19:9-16, 1997

59. Kast R, Auner G, Yurgelevic S, Broadbent B, Raghunathan A, Poisson LM, et al: Identification of regions of normal grey matter and white matter from pathologic glioblastoma and necrosis in frozen sections using Raman imaging. $\mathbf{J}$ Neurooncol 125:287-295, 2015

60. Kazmi SM, Richards LM, Schrandt CJ, Davis MA, Dunn AK: Expanding applications, accuracy, and interpretation of laser speckle contrast imaging of cerebral blood flow. J Cereb Blood Flow Metab 35:1076-1084, 2015

61. Khurana VG, Seow K, Duke D: Intuitiveness, quality and utility of intraoperative fluorescence videoangiography: Australian Neurosurgical Experience. Br J Neurosurg 24:163-172, 2010

62. Kim A, Khurana M, Moriyama Y, Wilson BC: Quantification of in vivo fluorescence decoupled from the effects of tissue optical properties using fiber-optic spectroscopy measurements. J Biomed Opt 15:067006, 2010

63. Kim EH, Cho JM, Chang JH, Kim SH, Lee KS: Application of intraoperative indocyanine green videoangiography to brain tumor surgery. Acta Neurochir (Wien) 153:14871495,2011

64. Kirsch M, Schackert G, Salzer R, Krafft C: Raman spectroscopic imaging for in vivo detection of cerebral brain metastases. Anal Bioanal Chem 398: 1707-1713, 2010

65. Koc K, Anik I, Cabuk B, Ceylan S: Fluorescein sodiumguided surgery in glioblastoma multiforme: a prospective evaluation. Br J Neurosurg 22:99-103, 2008

66. Konecky SD, Owen CM, Rice T, Valdés PA, Kolste K, Wilson BC, et al: Spatial frequency domain tomography of protoporphyrin IX fluorescence in preclinical glioma models. J Biomed Opt 17:056008, 2012
67. Krafft C, Belay B, Bergner N, Romeike BF, Reichart R, Kalff R, et al: Advances in optical biopsy - correlation of malignancy and cell density of primary brain tumors using Raman microspectroscopic imaging. Analyst (Lond) 137:5533-5537, 2012

68. Krammer B, Plaetzer K: ALA and its clinical impact, from bench to bedside. Photochem Photobiol Sci 7:283-289, 2008

69. Krůpa P, Řehák S, Diaz-Garcia D, Filip S: Nanotechnology - new trends in the treatment of brain tumours. Acta Med (Hradec Kralove) 57:142-150, 2014

70. Kuroiwa T, Kajimoto Y, Ohta T: Comparison between operative findings on malignant glioma by a fluorescein surgical microscopy and histological findings. Neurol Res 21:130-134, 1999

71. Kuroiwa T, Kajimoto Y, Ohta T: Development of a fluorescein operative microscope for use during malignant glioma surgery: a technical note and preliminary report. Surg Neurol 50:41-49, 1998

72. Kut C, Chaichana KL, Xi J, Raza SM, Ye X, McVeigh ER, et al: Detection of human brain cancer infiltration ex vivo and in vivo using quantitative optical coherence tomography. Sci Transl Med 7:292ra100, 2015

73. Lakowicz JR: Principles of Fluorescence Spectroscopy, ed 3. New York: Springer, 2006

74. Lane B, Bohnstedt BN, Cohen-Gadol AA: A prospective comparative study of microscope-integrated intraoperative fluorescein and indocyanine videoangiography for clip ligation of complex cerebral aneurysms. J Neurosurg 122:618626, 2015

75. Lane BC, Cohen-Gadol AA: Fluorescein fluorescence use in the management of intracranial neoplastic and vascular lesions: a review and report of a new technique. Curr Drug Discov Technol 10:160-169, 2013

76. Lane BC, Cohen-Gadol AA: A prospective study of microscope-integrated intraoperative fluorescein videoangiography during arteriovenous malformation surgery: preliminary results. Neurosurg Focus 36(2):E15, 2014

77. Leslie DG, Kast RE, Poulik JM, Rabah R, Sood S, Auner $\mathrm{GW}$, et al: Identification of pediatric brain neoplasms using Raman spectroscopy. Pediatr Neurosurg 48:109-117, 2012

78. Li J, Lan Z, He M, You C: Assessment of microscopeintegrated indocyanine green angiography during intracranial aneurysm surgery: a retrospective study of 120 patients. Neurol India 57:453-459, 2009

79. Li Y, Rey-Dios R, Roberts DW, Valdés PA, Cohen-Gadol AA: Intraoperative fluorescence-guided resection of highgrade gliomas: a comparison of the present techniques and evolution of future strategies. World Neurosurg 82:175185,2014

80. Lin WC, Mahadevan-Jansen A, Johnson MD, Weil RJ, Toms SA: In vivo optical spectroscopy detects radiation damage in brain tissue. Neurosurgery 57:518-525, 2005

81. Lin WC, Sandberg DI, Bhatia S, Johnson M, Morrison G, Ragheb J: Optical spectroscopy for in-vitro differentiation of pediatric neoplastic and epileptogenic brain lesions. J Biomed Opt 14:014028, 2009

82. Lin WC, Sandberg DI, Bhatia S, Johnson M, Oh S, Ragheb J: Diffuse reflectance spectroscopy for in vivo pediatric brain tumor detection. J Biomed Opt 15:061709, 2010

83. Lin WC, Toms SA, Johnson M, Jansen ED, MahadevanJansen A: In vivo brain tumor demarcation using optical spectroscopy. Photochem Photobiol 73:396-402, 2001

84. Lin WC, Toms SA, Motamedi M, Jansen ED, MahadevanJansen A: Brain tumor demarcation using optical spectroscopy; an in vitro study. J Biomed Opt 5:214-220, 2000

85. Litvack ZN, Zada G, Laws ER Jr: Indocyanine green fluorescence endoscopy for visual differentiation of pituitary 
tumor from surrounding structures. J Neurosurg 116:935941,2012

86. Macknik SL, Haglund MM: Optical images of visible and invisible percepts in the primary visual cortex of primates. Proc Natl Acad Sci U S A 96: 15208-15210, 1999

87. Marcu L, Jo JA, Butte PV, Yong WH, Pikul BK, Black KL, et al: Fluorescence lifetime spectroscopy of glioblastoma multiforme. Photochem Photobiol 80:98-103, 2004

88. Martirosyan NL, Cavalcanti DD, Eschbacher JM, Delaney PM, Scheck AC, Abdelwahab MG, et al: Use of in vivo near-infrared laser confocal endomicroscopy with indocyanine green to detect the boundary of infiltrative tumor. $\mathbf{J}$ Neurosurg 115:1131-1138, 2011

89. Mattei TA, Rehman AA: "Extremely minimally invasive": recent advances in nanotechnology research and future applications in neurosurgery. Neurosurg Rev 38:27-37, 2015

90. Montcel B, Mahieu-Williame L, Armoiry X, Meyronet D, Guyotat J: Two-peaked 5-ALA-induced PpIX fluorescence emission spectrum distinguishes glioblastomas from low grade gliomas and infiltrative component of glioblastomas. Biomed Opt Express 4:548-558, 2013

91. Mooney MA, Zehri AH, Georges JF, Nakaji P: Laser scanning confocal endomicroscopy in the neurosurgical operating room: a review and discussion of future applications. Neurosurg Focus 36(2):E9, 2014

92. Moore GE, Peyton WT, French LA, Walker WW: The clinical use of fluorescein in neurosurgery; the localization of brain tumors. J Neurosurg 5:392-398, 1948

93. Moriyama EH, Bisland SK, Lilge L, Wilson BC: Bioluminescence imaging of the response of rat gliosarcoma to ALA-PpIX-mediated photodynamic therapy. Photochem Photobiol 80:242-249, 2004

94. Morofuji Y, Matsuo T, Hayashi Y, Suyama K, Nagata I: Usefulness of intraoperative photodynamic diagnosis using 5 -aminolevulinic acid for meningiomas with cranial invasion: technical case report. Neurosurgery 62 (3 Suppl 1):102-104, 2008

95. Murray KJ: Improved surgical resection of human brain tumors: Part I. A preliminary study. Surg Neurol 17:316319,1982

96. Novotny A, Xiang J, Stummer W, Teuscher NS, Smith DE, Keep RF: Mechanisms of 5-aminolevulinic acid uptake at the choroid plexus. J Neurochem 75:321-328, 2000

97. Ntziachristos V, Yoo JS, van Dam GM: Current concepts and future perspectives on surgical optical imaging in cancer. J Biomed Opt 15:066024, 2010

98. Okuda T, Kataoka K, Taneda M: Metastatic brain tumor surgery using fluorescein sodium: technical note. Minim Invasive Neurosurg 50:382-384, 2007

99. Panciani PP, Fontanella M, Schatlo B, Garbossa D, Agnoletti A, Ducati A, et al: Fluorescence and image guided resection in high grade glioma. Clin Neurol Neurosurg 114:37-41, 2012

100. Parthasarathy AB, Weber EL, Richards LM, Fox DJ, Dunn AK: Laser speckle contrast imaging of cerebral blood flow in humans during neurosurgery: a pilot clinical study. $\mathbf{J}$ Biomed Opt 15:066030, 2010

101. Peng Q, Warloe T, Berg K, Moan J, Kongshaug M, Giercksky KE, et al: 5-Aminolevulinic acid-based photodynamic therapy. Clinical research and future challenges. Cancer 79:2282-2308, 1997

102. Pichlmeier U, Bink A, Schackert G, Stummer W: Resection and survival in glioblastoma multiforme: an RTOG recursive partitioning analysis of ALA study patients. Neuro Oncol 10:1025-1034, 2008

103. Pogue BW, Gibbs-Strauss S, Valdés PA, Samkoe K, Roberts DW, Paulsen KD: Review of neurosurgical fluorescence imaging methodologies. IEEE J Sel Top Quantum Electron 16:493-505, 2010
104. Pouratian N, Sheth S, Bookheimer SY, Martin NA, Toga AW: Applications and limitations of perfusion-dependent functional brain mapping for neurosurgical guidance. Neurosurg Focus 15(1):E2, 2003

105. Pouratian N, Sheth SA, Martin NA, Toga AW: Shedding light on brain mapping: advances in human optical imaging. Trends Neurosci 26:277-282, 2003

106. Prakash N, Uhlemann F, Sheth SA, Bookheimer S, Martin $\mathrm{N}$, Toga AW: Current trends in intraoperative optical imaging for functional brain mapping and delineation of lesions of language cortex. Neuroimage 47 (Suppl 2):T116-T126, 2009

107. Raabe A, Beck J, Gerlach R, Zimmermann M, Seifert V: Near-infrared indocyanine green video angiography: a new method for intraoperative assessment of vascular flow. Neurosurgery 52:132-139, 2003

108. Raabe A, Beck J, Seifert V: Technique and image quality of intraoperative indocyanine green angiography during aneurysm surgery using surgical microscope integrated nearinfrared video technology. Zentralbl Neurochir 66:1-8, 2005

109. Raabe A, Nakaji P, Beck J, Kim LJ, Hsu FP, Kamerman JD, et al: Prospective evaluation of surgical microscopeintegrated intraoperative near-infrared indocyanine green videoangiography during aneurysm surgery. J Neurosurg 103:982-989, 2005

110. Ramanujam N: Fluorescence spectroscopy of neoplastic and non-neoplastic tissues. Neoplasia 2:89-117, 2000

111. Rey-Dios R, Cohen-Gadol AA: Technical principles and neurosurgical applications of fluorescein fluorescence using a microscope-integrated fluorescence module. Acta Neurochir (Wien) 155:701-706, 2013

112. Rey-Dios R, Hattab EM, Cohen-Gadol AA: Use of intraoperative fluorescein sodium fluorescence to improve the accuracy of tissue diagnosis during stereotactic needle biopsy of high-grade gliomas. Acta Neurochir (Wien) 156:1071-1075, 2014

113. Richards LM, Towle EL, Fox DJ Jr, Dunn AK: Intraoperative laser speckle contrast imaging with retrospective motion correction for quantitative assessment of cerebral blood flow. Neurophotonics 1:015006, 2014

114. Richards-Kortum R, Sevick-Muraca E: Quantitative optical spectroscopy for tissue diagnosis. Annu Rev Phys Chem 47:555-606, 1996

115. Richter JC, Haj-Hosseini N, Andersson-Engel S, Wårdell $\mathrm{K}$ : Fluorescence spectroscopy measurements in ultrasonic navigated resection of malignant brain tumors. Lasers Surg Med 43:8-14, 2011

116. Roberts DW, Valdés PA, Harris BT, Fontaine KM, Hartov A, Fan X, et al: Coregistered fluorescence-enhanced tumor resection of malignant glioma: relationships between $\delta$-aminolevulinic acid-induced protoporphyrin IX fluorescence, magnetic resonance imaging enhancement, and neuropathological parameters. Clinical article. J Neurosurg 114:595-603, 2011

117. Romeike BF, Meyer T, Reichart R, Kalff R, Petersen I, Dietzek B, et al: Coherent anti-Stokes Raman scattering and two photon excited fluorescence for neurosurgery. Clin Neurol Neurosurg 131:42-46, 2015

118. Rutka JT, Kim B, Etame A, Diaz RJ: Nanosurgical resection of malignant brain tumors: beyond the cutting edge. ACS Nano 8:9716-9722, 2014

119. Sanai N, Berger MS: Glioma extent of resection and its impact on patient outcome. Neurosurgery 62:753-764, 264-266, 2008

120. Sanai N, Eschbacher J, Hattendorf G, Coons SW, Preul $\mathrm{MC}$, Smith KA, et al: Intraoperative confocal microscopy for brain tumors: a feasibility analysis in humans. Neurosurgery 68 (2 Suppl Operative):282-290, 2011 
121. Sanai N, Polley MY, McDermott MW, Parsa AT, Berger MS: An extent of resection threshold for newly diagnosed glioblastomas. J Neurosurg 115:3-8, 2011

122. Sanai N, Snyder LA, Honea NJ, Coons SW, Eschbacher JM, Smith KA, et al: Intraoperative confocal microscopy in the visualization of 5-aminolevulinic acid fluorescence in low-grade gliomas. J Neurosurg 115:740-748, 2011

123. Sankar T, Delaney PM, Ryan RW, Eschbacher J, Abdelwahab M, Nakaji P, et al: Miniaturized handheld confocal microscopy for neurosurgery: results in an experimental glioblastoma model. Neurosurgery 66:410-418, 2010

124. Schebesch KM, Proescholdt M, Brawanski A: Fluorescein sodium in brain tumor surgery - Response. Acta Neurochir (Wien) 155:2253-2254, 2013

125. Schebesch KM, Proescholdt M, Höhne J, Hohenberger C, Hansen E, Riemenschneider MJ, et al: Sodium fluoresceinguided resection under the YELLOW $560 \mathrm{~nm}$ surgical microscope filter in malignant brain tumor surgery - a feasibility study. Acta Neurochir (Wien) 155:693-699, 2013

126. Schlosser HG, Suess O, Vajkoczy P, van Landeghem FK, Zeitz M, Bojarski C: Confocal neurolasermicroscopy in human brain - perspectives for neurosurgery on a cellular level (including additional comments to this article). Cent Eur Neurosurg 71:13-19, 2010

127. Stepp H, Beck T, Pongratz T, Meinel T, Kreth FW, Tonn JCh, et al: ALA and malignant glioma: fluorescence-guided resection and photodynamic treatment. J Environ Pathol Toxicol Oncol 26: 157-164, 2007

128. Stummer W: Fluorescein for vascular and oncological neurosurgery. Acta Neurochir (Wien) 155:1477-1478, 2013

129. Stummer W: Response to journal club: 5-aminolevulinic acid-derived tumor fluorescence: the diagnostic accuracy of visible fluorescence qualities as corroborated by spectrometry and histology and postoperative imaging. Neurosurgery 76:230-231, 2015

130. Stummer W, Beck T, Beyer W, Mehrkens JH, Obermeier A, Etminan N, et al: Long-sustaining response in a patient with non-resectable, distant recurrence of glioblastoma multiforme treated by interstitial photodynamic therapy using 5-ALA: case report. J Neurooncol 87:103-109, 2008

131. Stummer W, Novotny A, Stepp H, Goetz C, Bise K, Reulen HJ: Fluorescence-guided resection of glioblastoma multiforme by using 5-aminolevulinic acid-induced porphyrins: a prospective study in 52 consecutive patients. J Neurosurg 93: $1003-1013,2000$

132. Stummer W, Pichlmeier U, Meinel T, Wiestler OD, Zanella F, Reulen HJ: Fluorescence-guided surgery with 5-aminolevulinic acid for resection of malignant glioma: a randomised controlled multicentre phase III trial. Lancet Oncol 7:392-401, 2006

133. Stummer W, Reulen HJ, Meinel T, Pichlmeier U, Schumacher W, Tonn JC, et al: Extent of resection and survival in glioblastoma multiforme: identification of and adjustment for bias. Neurosurgery 62:564-576, 2008

134. Stummer W, Stocker S, Wagner S, Stepp H, Fritsch C, Goetz C, et al: Intraoperative detection of malignant gliomas by 5 -aminolevulinic acid-induced porphyrin fluorescence. Neurosurgery 42:518-526, 1998

135. Stummer W, Tonn JC, Goetz C, Ullrich W, Stepp H, Bink A, et al: 5-Aminolevulinic acid-derived tumor fluorescence: the diagnostic accuracy of visible fluorescence qualities as corroborated by spectrometry and histology and postoperative imaging. Neurosurgery 74:310-320, 2014

136. Stummer W, Tonn JC, Mehdorn HM, Nestler U, Franz $\mathrm{K}$, Goetz C, et al: Counterbalancing risks and gains from extended resections in malignant glioma surgery: a supplemental analysis from the randomized 5-aminolevulinic acid glioma resection study. Clinical article. J Neurosurg 114:613-623, 2011
137. Sun Y, Hatami N, Yee M, Phipps J, Elson DS, Gorin F, et al: Fluorescence lifetime imaging microscopy for brain tumor image-guided surgery. J Biomed Opt 15:056022, 2010

138. Suzuki T, Wada S, Eguchi H, Adachi J, Mishima K, Matsutani M, et al: Cadherin 13 overexpression as an important factor related to the absence of tumor fluorescence in 5-aminolevulinic acid-guided resection of glioma. J Neurosurg 119:1331-1339, 2013

139. Toms SA, Konrad PE, Lin WC, Weil RJ: Neuro-oncological applications of optical spectroscopy. Technol Cancer Res Treat 5:231-238, 2006

140. Toms SA, Lin WC, Weil RJ, Johnson MD, Jansen ED, Mahadevan-Jansen A: Intraoperative optical spectroscopy identifies infiltrating glioma margins with high sensitivity. Neurosurgery 61 (1 Suppl):SHC-327-SHC-336, 2007

141. Toms SA, Lin WC, Weil RJ, Johnson MD, Jansen ED, Mahadevan-Jansen A: Intraoperative optical spectroscopy identifies infiltrating glioma margins with high sensitivity. Neurosurgery 57 (4 Suppl):382-391, 2005

142. Tréhin R, Figueiredo JL, Pittet MJ, Weissleder R, Josephson L, Mahmood U: Fluorescent nanoparticle uptake for brain tumor visualization. Neoplasia 8:302-311, 2006

143. Uckermann O, Galli R, Tamosaityte S, Leipnitz E, Geiger $\mathrm{KD}$, Schackert G, et al: Label-free delineation of brain tumors by coherent anti-Stokes Raman scattering microscopy in an orthotopic mouse model and human glioblastoma. PLoS One 9:e107115, 2014

144. Utsuki S, Miyoshi N, Oka H, Miyajima Y, Shimizu S, Suzuki S, et al: Fluorescence-guided resection of metastatic brain tumors using a 5-aminolevulinic acid-induced protoporphyrin IX: pathological study. Brain Tumor Pathol 24:53-55, 2007

145. Utsuki S, Oka H, Miyajima Y, Shimizu S, Suzuki S, Fujii $\mathrm{K}$ : Auditory alert system for fluorescence-guided resection of gliomas. Neurol Med Chir (Tokyo) 48:95-98, 2008

146. Utsuki S, Oka H, Sato S, Shimizu S, Suzuki S, Tanizaki Y, et al: Histological examination of false positive tissue resection using 5-aminolevulinic acid-induced fluorescence guidance. Neurol Med Chir (Tokyo) 47:210-214, 2007

147. Utsuki S, Oka H, Sato S, Suzuki S, Shimizu S, Tanaka S, et al: Possibility of using laser spectroscopy for the intraoperative detection of nonfluorescing brain tumors and the boundaries of brain tumor infiltrates. Technical note. J Neurosurg 104:618-620, 2006

148. Valdés PA, Bekelis K, Harris BT, Wilson BC, Leblond F, Kim A, et al: 5-Aminolevulinic acid-induced protoporphyrin IX fluorescence in meningioma: qualitative and quantitative measurements in vivo. Neurosurgery 10 (Suppl 1):74-83, 2014

149. Valdés PA, Fan X, Ji S, Harris BT, Paulsen KD, Roberts DW: Estimation of brain deformation for volumetric image updating in protoporphyrin IX fluorescence-guided resection. Stereotact Funct Neurosurg 88:1-10, 2010

150. Valdés PA, Jacobs V, Harris BT, Wilson BC, Leblond F, Paulsen KD, et al: Quantitative fluorescence using 5-aminolevulinic acid-induced protoporphyrin IX biomarker as a surgical adjunct in low-grade glioma surgery. J Neurosurg 123:771-780, 2015

151. Valdés PA, Leblond F, Jacobs VL, Paulsen KD, Roberts DW: In vivo fluorescence detection in surgery: A review of principles, methods, and applications. Curr Med Imaging Rev 8:211-232, 2012

152. Valdés PA, Jacobs VL, Wilson BC, Leblond F, Roberts DW, Paulsen KD: System and methods for wide-field quantitative fluorescence imaging during neurosurgery. Opt Lett 38:2786-2788, 2013

153. Valdés PA, Kim A, Brantsch M, Niu C, Moses ZB, Tosteson TD, et al: $\delta$-aminolevulinic acid-induced pro- 
toporphyrin IX concentration correlates with histopathologic markers of malignancy in human gliomas: the need for quantitative fluorescence-guided resection to identify regions of increasing malignancy. Neuro Oncol 13:846856, 2011

154. Valdés PA, Kim A, Leblond F, Conde OM, Harris BT, Paulsen KD, et al: Combined fluorescence and reflectance spectroscopy for in vivo quantification of cancer biomarkers in low- and high-grade glioma surgery. J Biomed Opt 16: 116007,2011

155. Valdés PA, Leblond F, Jacobs VL, Wilson BC, Paulsen KD, Roberts DW: Quantitative, spectrally-resolved intraoperative fluorescence imaging. Sci Rep 2:798, 2012

156. Valdés PA, Leblond F, Kim A, Harris BT, Wilson BC, Fan $X$, et al: Quantitative fluorescence in intracranial tumor: implications for ALA-induced PpIX as an intraoperative biomarker. J Neurosurg 115:11-17, 2011

157. Valdés PA, Leblond F, Kim A, Wilson BC, Paulsen KD, Roberts DW: A spectrally constrained dual-band normalization technique for protoporphyrin IX quantification in fluorescence-guided surgery. Opt Lett 37:1817-1819, 2012

158. Valdés PA, Moses ZB, Kim A, Belden CJ, Wilson BC, Paulsen KD, et al: Gadolinium- and 5-aminolevulinic acidinduced protoporphyrin IX levels in human gliomas: an ex vivo quantitative study to correlate protoporphyrin IX levels and blood-brain barrier breakdown. J Neuropathol Exp Neurol 71:806-813, 2012

159. Valdés PA, Samkoe K, O'Hara JA, Roberts DW, Paulsen $\mathrm{KD}$, Pogue BW: Deferoxamine iron chelation increases delta-aminolevulinic acid induced protoporphyrin IX in xenograft glioma model. Photochem Photobiol 86:471-475, 2010

160. Van Meir EG, Hadjipanayis CG, Norden AD, Shu HK, Wen $\mathrm{PY}$, Olson JJ: Exciting new advances in neuro-oncology: the avenue to a cure for malignant glioma. CA Cancer J Clin 60:166-193, 2010

161. Vervandier J, Gioux S: Single snapshot imaging of optical properties. Biomed Opt Express 4:2938-2944, 2013

162. Weissleder R, Pittet MJ: Imaging in the era of molecular oncology. Nature 452:580-589, 2008

163. Whitney MA, Crisp JL, Nguyen LT, Friedman B, Gross LA, Steinbach P, et al: Fluorescent peptides highlight peripheral nerves during surgery in mice. Nat Biotechnol 29:352-356, 2011

164. Widhalm G, Wolfsberger S, Minchev G, Woehrer A, Krssak $\mathrm{M}$, Czech T, et al: 5-Aminolevulinic acid is a promising marker for detection of anaplastic foci in diffusely infiltrating gliomas with nonsignificant contrast enhancement. Cancer 116: 1545-1552, 2010

165. Woitzik J, Horn P, Vajkoczy P, Schmiedek P: Intraoperative control of extracranial-intracranial bypass patency by nearinfrared indocyanine green videoangiography. J Neurosurg 102:692-698, 2005

166. Woitzik J, Peña-Tapia PG, Schneider UC, Vajkoczy P, Thomé C: Cortical perfusion measurement by indocyanine- green videoangiography in patients undergoing hemicraniectomy for malignant stroke. Stroke 37:1549-1551, 2006

167. Yamada S, Muragaki Y, Maruyama T, Komori T, Okada Y: Role of neurochemical navigation with 5-aminolevulinic acid during intraoperative MRI-guided resection of intracranial malignant gliomas. Clin Neurol Neurosurg 130:134139,2015

168. Yang B, Sharma M, Tunnell JW: Attenuation-corrected fluorescence extraction for image-guided surgery in spatial frequency domain. J Biomed Opt 18:80503, 2013

169. Yang VX, Muller PJ, Herman P, Wilson BC: A multispectral fluorescence imaging system: design and initial clinical tests in intra-operative Photofrin-photodynamic therapy of brain tumors. Lasers Surg Med 32:224-232, 2003

170. Yong WH, Butte PV, Pikul BK, Jo JA, Fang Q, Papaioannou T, et al: Distinction of brain tissue, low grade and high grade glioma with time-resolved fluorescence spectroscopy. Front Biosci 11: 1255-1263, 2006

171. Yuan B, Chen N, Zhu Q: Emission and absorption properties of indocyanine green in Intralipid solution. J Biomed Opt 9:497-503, 2004

172. Zehri AH, Ramey W, Georges JF, Mooney MA, Martirosyan NL, Preul MC, et al: Neurosurgical confocal endomicroscopy: A review of contrast agents, confocal systems, and future imaging modalities. Surg Neurol Int 5:60, 2014

173. Zhou Y, Liu CH, Sun Y, Pu Y, Boydston-White S, Liu Y, et al: Human brain cancer studied by resonance Raman spectroscopy. J Biomed Opt 17:116021, 2012

174. Zimmermann A, Ritsch-Marte M, Kostron H: mTHPCmediated photodynamic diagnosis of malignant brain tumors. Photochem Photobiol 74:611-616, 2001

\section{Disclosures}

Drs. Valdés and Roberts have multiple patents for intraoperative probes and imaging devices noted in this paper. Dr. Roberts reports receiving research support from Zeiss, Medtronic, and Dusa Pharmaceuticals.

\section{Author Contributions}

Conception and design: Valdés, Roberts, Golby. Acquisition of data: Valdés, Lu. Analysis and interpretation of data: Valdés, Lu, Golby. Drafting the article: Valdés. Critically revising the article: all authors. Reviewed submitted version of manuscript: all authors. Approved the final version of the manuscript on behalf of all authors: Valdés. Administrative/technical/material support: Golby. Study supervision: Valdés, Golby.

\section{Correspondence}

Pablo A. Valdés, Department of Neurosurgery, Harvard Medical School, Brigham and Women's Hospital, 75 Francis St., Boston, MA 02115. email: pvaldesquevedo@partners.org. 